OPEN ACCESS

Edited by: Hongchen Jiang,

Miami University, United States

Reviewed by:

Baozhan Wang

Institute of Soil Science (CAS), China

Qingyun Yan,

Sun Yat-sen University, China

*Correspondence:

Ji-Dong Gu

jdgu@hku.hk

Meng $\mathrm{Li}$

limeng848@szu.edu.cn

Specialty section:

This article was submitted to

Terrestrial Microbiology

a section of the journal

Frontiers in Microbiology

Received: 07 August 2017

Accepted: 20 October 2017

Published: 02 November 2017

Citation:

Zhou Z, Meng H, Liu Y, Gu J-D and

Li M (2017) Stratified Bacterial and

Archaeal Community in Mangrove and Intertidal Wetland Mudflats Revealed by High Throughput 16 S rRNA Gene Sequencing. Front. Microbiol. 8:2148.

doi: 10.3389/fmicb.2017.02148

\section{Stratified Bacterial and Archaeal Community in Mangrove and Intertidal Wetland Mudflats Revealed by High Throughput 16S rRNA Gene Sequencing}

\author{
Zhichao Zhou ${ }^{1}$, Han Meng ${ }^{1}$, Yang Liu ${ }^{2}$, Ji-Dong Gu ${ }^{1 *}$ and Meng $L i^{2 *}$ \\ 1 Laboratory of Environmental Microbiology and Toxicology, School of Biological Sciences, University of Hong Kong, \\ Pokfulam, Hong Kong, ${ }^{2}$ Institute for Advanced Study, Shenzhen University, Shenzhen, China
}

The stratified distribution of bacterial and archaeal communities has been detected in many sediment profiles from various natural environments. A better understanding of microbial composition and diversity pattern in coastal mangrove wetlands in relation to physicochemical and spatial-temporal influences could provide more insights into the ecological functions of microbes in coastal wetlands. In this study, seasonal variations of microbial communities within sediment profiles from two sediment types (mangrove forest and intertidal mudflats) at three sampling locations in coastal Mai Po wetland were characterized using MiSeq high throughput sequencing and 16S rRNA quantitative PCR methods. Bacterial 16S rRNA gene abundance showed clear decreasing trends with increasing depth for all sites, seasonality and sediment types. There is a weak seasonal dynamic of bacterial and archaeal community abundance in both seasons. Seasonality imposed more influence on the beta diversity pattern of bacterial community than archaeal community. The five most abundant phyla within bacterial and archaeal community remain stable between two distinctive seasons. Sediment depth and seasonality are the most influential factors affecting bacterial community composition and diversity. The $\mathrm{pH}$ is the most influential factor on shaping the archaeal community. Stratified distribution of bacterial community including aerobic and anaerobic bacterial taxa is largely represented in the surface layers and the subsurface layers, respectively. For archaeal stratification, Thaumarchaeota Marine Group I is the dominant member in surface sediments while Bathyarchaeota and MBG-B dominate in subsurface sediments. Such stratified distribution patterns are irrespective of sediment types, sampling locations or seasonality, but significantly correlated to the sediment depth, which might be shaped by oxygen availability and the distribution of other terminal electron accepters along the depth profile.

\footnotetext{
Keywords: stratification, microbial community, mangrove wetlands, sediment profiles, pH, seasonality
} 


\section{INTRODUCTION}

Coastal mangrove forest is one of the most important integrated ecosystems mainly distributed in the tropical or subtropical coastline and estuarine areas with significant ecological functions, such as filtering and reducing dissolved and particulate nutrients, serving as a sink for carbon, nitrogen and phosphorus, as well as retaining heavy metals from adjacent land and fluvial imports (Zheng et al., 2000; Reef et al., 2010; Alongi, 2014; Sanders et al., 2014). The mangrove forests, characterized as highly productive ecosystems, contribute to $10-15 \%$ global coast sediment carbon storage, and provide nutrients and habitats for microorganisms, micro-/marco-fauna, and migratory birds (Yan et al., 2006; Alongi, 2014; Bhattacharyya et al., 2015). The microorganisms inhabiting mangrove forests have important roles in facilitating carbon, sulfate, nitrogen and phosphorus cycles as well as promoting plant growth by generating phytohormone and siderophore (Holguin et al., 2001). Increasing researches are focused on the distribution pattern and potential biogeochemical functions in mangrove ecosystems (Nedwell et al., 1994; Yan et al., 2006; Sahoo and Dhal, 2009; Wang et al., 2012; Jiang et al., 2013; Bhattacharyya et al., 2015). Linking microbial distribution and diversity pattern to environmental factors would allow better understanding of ecosystem functions and biogeochemical processes within the local wetland, thus facilitating the wetland management and sustainable development (Sims et al., 2013; Ansola et al., 2014; Arroyo et al., 2015).

Mai Po Nature Reserve locates at the northwestern coastal region of Hong Kong, facing Deep Bay, and it is influenced by discharges from Shenzhen River and Pearl River. Mai Po Nature Reserve is the largest wetland in Hong Kong, listed as a Ramsar Site for its importance of environmental reservation and management (Liang and Wong, 2003). Its ecological importance is renowned for offering conservation of micro-/macro-fauna, migratory birds, and mangrove forests which mainly dominated by Kandelia obovata and Avicennia marina (Lee, 1999; Jia et al., 2014). It contains several man-made and natural eco-niches, including, fresh water ponds, reedbeds, Gei Wai (semi-enclosed shrimp ponds), mangrove forests and fringe intertidal mudflats. The rapid urbanization and industrialization coupled with fast population augmentation around the Pearl River Delta Zone have taken place during the economic boost over the last several decades in South China (Lee et al., 2006). It has imposed large environmental stress, such as heavy metals, organic pollutions and eutrophication impacts on the estuarine regions, as well as western coastal water of Hong Kong (Zheng et al., 2000; Cheung et al., 2003; Liang and Wong, 2003). The catchments of local rivers (such as Shan Pui River and Kam Tin River) for livestock (such as poultry and animal husbandry) and domestic sewage in northwestern New Territories have also deteriorated the ecological conditions (Lau and Chu, 1999; Lee, 1999).

The recent research found the spatial distribution of bacterial communities toward the horizontal and vertical gradients of freshwater lakeside sediments (Ding et al., 2015). The variable biogeochemical zonation along the depth profile involves the mineralization process, and could largely determine bacterial community distribution patterns (Wilms et al., 2006; Canfield and Thamdrup, 2009; O'sullivan et al., 2013; Ding et al., 2015). Many studies also revealed many influential factors, such as wetland types (constructed or natural wetland), water contents, organic matters, total Kjeldahl Nitrogen (TKN), chemical oxygen demand (COD), inorganic nitrogen $\left(\mathrm{NH}_{4}^{+}\right.$and $\mathrm{NO}_{3}^{-}$) and $\mathrm{pH}$ are determinants of soil bacterial community composition and structure (Fierer et al., 2003; Drenovsky et al., 2004; Ansola et al., 2014; Ligi et al., 2014; Arroyo et al., 2015; Ding et al., 2015). Meanwhile, temporal variables of seasonality could also influence the bacterial diversity pattern, and community composition and abundance of certain functional groups (Wang et al., 2013; Lu et al., 2016). Stratified distribution of archaeal community in estuarine sediment depth profiles has been well documented regarding to compositional patterns between surface and subsurface sediments (Webster et al., 2010; Jiang et al., 2011; Li et al., 2012). Recently, comparison of the bacterial community difference among mangrove wetlands, marine sediments and freshwater sediments was reported (Wang et al., 2012). The bacterial community composition and diversity between inner and outer mangrove forest sediments revealed spatial variation among sediment types (Jiang et al., 2013). However, most of the above researches have seldom paid an integrative view on microbial distribution and diversity patterns toward spatial and temporal scales, and statistically summarize the pattern reflected in a whole ecosystem. Bacterial and archaeal community distributing pattern toward depth profiles, sediment types, seasonality, and sampling locations in coastal mangrove wetlands still need to be comprehensively analyzed. The potential linkage between the physicochemical factors and microbial community remains elusive; it is fundamental to address the underlying mechanism for the formation of nichespecific microbial community structures and functions and their ecological roles in local biogeochemical processes (O'sullivan et al., 2013; Ansola et al., 2014; Ligi et al., 2014; Arroyo et al., 2015).

The rapid development of high throughput sequencing techniques and related bioinformatic approaches have allowed the exploration of microbial community with sufficient sequence coverage and equal sampling scale, which enables robust and comprehensive assessment on reflecting microbial distribution pattern (Dowd et al., 2008; Schloss et al., 2009; Caporaso et al., 2010, 2012; Angiuoli et al., 2011; Quast et al., 2013; Cole et al., 2014). In this study, the Illumina MiSeq based on 16S rRNA genes high throughput sequencing method was applied to study the temporal and spatial variation influence, including vertical distribution pattern, sampling locations and sediment types together with the seasonality influence, on the microbial community structure in Mai Po wetland. The microbial distribution patterns within depth profiles from two sediment types, mangrove forest (MG) and intertidal mudflats (TF), were compared and analyzed. It is aimed to characterize stratified microbial communities and their composition and diversity patterns in relation to the physicochemical factors. 


\section{MATERIALS AND METHODS}

\section{Sampling, Physicochemical Parameter Measurement and DNA Isolation}

Samples were taken in Mai Po Nature Reserve, a coastal wetland located at Shenzhen River estuary and facing the Inner Deep Bay (Shenzhen Bay) (Figure 1). Three sites were chosen from mangrove forest (MG1-3) and another three were from intertidal mudflats (TF1-3). At each site of mangrove forest, four layers of sediment were collected in winter and three layers were collected in summer. At each site of intertidal mudflats, two layers of sediments were collected in both two seasons (Table 1). Bulk sediments were sealed into plastic bags immediately after collection and stored in pre-cold sampling box immediately, then transported to laboratory. For each sample, $5 \mathrm{~g}$ of wet sediments were used for physicochemical parameter measurement and the remaining was stored in $-20^{\circ} \mathrm{C}$ refrigerator for further DNA isolation.

The physicochemical parameters, including $\mathrm{pH}$, redox potential, water content, $\mathrm{NH}_{4}^{+}, \mathrm{NO}_{2}^{-}$, and $\mathrm{NO}_{3}^{-}$concentrations, organic matter content, were measured using procedures as previously reported (Cao et al., 2012; Li et al., 2013). For DNA isolation, $0.25 \mathrm{~g}$ of wet sediments from each sample were used for metagenomic DNA isolation by PowerSoil ${ }^{\circledR}$ DNA Isolation Kit ( $\mathrm{MO} \mathrm{BIO})$ and the procedures were those of the manufacturer's. The water contents of sediment samples were determined after heating in $105^{\circ} \mathrm{C}$ oven over night and DNA concentration in dry sediment was used in the final expression of results.

\section{MiSeq Based 16S rRNA Gene High throughput Sequencing}

In order to acquire specific archaeal 16S rRNA gene libraries from all samples, a nested PCR procedure was adopted. Long fragment targeting primer pair 21F/958R was used for the first step (DeLong, 1992), subsequently, successfully obtained and purified PCR products were applied as DNA templates for the second PCR step by using Arch349F/Arch806R (Takai and Horikoshi, 2000 ) as the primer pair (12 nt unique barcode was added to $5^{\prime}$ of Arch349F as indexing)(Caporaso et al., 2012). The PCR reaction mixture contained: $5 \mu \mathrm{l}$ of $5 \times$ GoTaq buffer (Promega), $5 \mathrm{nmol}$ of dNTPs, $62.5 \mathrm{nmol}$ of $\mathrm{Mg}^{2+}, 10 \mu \mathrm{g}$ of BSA $(10 \mathrm{mg} / \mathrm{ml}$, Roche), $0.5 \mu \mathrm{l}$ of forward and reverse primer $(20 \mu \mathrm{M}), 1 \mu \mathrm{l}$ of DNA template $(0-25 \mathrm{ng} / \mu \mathrm{l})$ and $0.2 \mu \mathrm{l}$ of GoTaq polymerase (5 U/ $/$ l, Promega) and $\mathrm{ddH}_{2} \mathrm{O}$ to make up a total volume to $25 \mu$ l. The PCR thermocycling setting for the first PCR step (21F/958R) was as following: firstly pre-heating $95^{\circ} \mathrm{C}$ for $5 \mathrm{~min}$; then 33 cycles of $95^{\circ} \mathrm{C} 30 \mathrm{~s}, 52^{\circ} \mathrm{C} 30 \mathrm{~s}$ and $72^{\circ} \mathrm{C} 90 \mathrm{~s}$; finally $72^{\circ} \mathrm{C}$ for $10 \mathrm{~min}$ and $4^{\circ} \mathrm{C}$ for $2 \mathrm{~min}$. The PCR thermocycling setting for the second PCR step (Arch349F/Arch806R) was as following: firstly preheating $95^{\circ} \mathrm{C}$ for $5 \mathrm{~min}$; then 15 cycles of $95^{\circ} \mathrm{C} 30 \mathrm{~s}$, $50^{\circ} \mathrm{C} 30 \mathrm{~s}$ and $72^{\circ} \mathrm{C} 40 \mathrm{~s}$; finally $72^{\circ} \mathrm{C}$ for $10 \mathrm{~min}$ and $4^{\circ} \mathrm{C}$ for $2 \mathrm{~min}$. For microbial 16S rRNA gene library construction, the primer pair $515 \mathrm{~F} / 909 \mathrm{~F}$ was applied to cover the $16 \mathrm{~S}$ hypervariable $\mathrm{V} 4-\mathrm{V} 5$ regions (12 nt unique barcode was added to $5^{\prime}$ of $515 \mathrm{~F}$ as indexing) (Wang and Qian, 2009; Caporaso et al., 2012). The PCR thermocycling setting was as following: firstly pre-heating $95^{\circ} \mathrm{C}$ for $5 \mathrm{~min}$; then $33 \mathrm{cycles}$ of $95^{\circ} \mathrm{C} 30 \mathrm{~s}, 52^{\circ} \mathrm{C} 30 \mathrm{~s}$ and $72^{\circ} \mathrm{C}$
$90 \mathrm{~s}$; finally $72^{\circ} \mathrm{C}$ for $10 \mathrm{~min}$ and $4^{\circ} \mathrm{C}$ for $2 \mathrm{~min}$. The mixture for microbial 16S rRNA gene PCR was similar to that of archaeal $16 S$ rRNA gene PCR, except for replacing each forward and reverse primer volume to $1 \mu \mathrm{l}(20 \mu \mathrm{M})$. Every PCR reaction was conducted separately for duplicates and PCR products were pooled into one to obtain enough quantity and compromise PCR bias between batches. Then, each obtained PCR product was subjected to electrophoresis using 1\% agarose gel. Clear bands with proper length were cut out and purified by illustra GFX PCR DNA and Gel Band Purification Kit (GE Healthcare). The concentrations of purified amplicons were measured by Nanodrop. Purified amplicons from all PCR libraries were pooled into one with the concentration to achieve $100 \mathrm{ng}$ for individual sample, and then subjected to MiSeq for high throughput sequencing. The sequencing samples were prepared using TruSeq DNA kit according to manufacturer's instruction. The purified library was diluted, denatured, re-diluted, and mixed with PhiX (equal to $30 \%$ of the final DNA amount) as described in the Illumina library preparation protocols, and then applied to an Illumina MiSeq system for sequencing with the reagent kit v2 (2 $\times 250 \mathrm{bp})$ or v3 $(2 \times 300 \mathrm{bp})$ as described in the manufacturer's manual.

\section{MiSeq Sequencing Data Process by QIIME}

Firstly, two pair end sequencing data were merged into one using FLASH-1.2.8, then, fastx-toolkit was applied to split the merged data from one run into individual samples according to the attached barcodes (Magoc and Salzberg, 2011). Finally, each library was assigned by using QIIME software command "split_libraries" according to the corresponding barcode map file (Caporaso et al., 2012). Filtering criterion was set as “-s 15 -k $-\mathrm{a} \quad 6$-r check was conducted by USEARCH software using QIIME compatible SILVA 119 release SSURef database "rdp_gold" fasta file as the reference (Edgar, 2010; Caporaso et al., 2012). After screening out the chimeric sequences from each library, sequences from all libraries were combined into one and subjected to OTU picking step, by applying the command "pick_open_reference_otus.py" with QIIME compatible SILVA 119 SSURef database (Silva_119_rep_set97.fna) as the reference. Open reference OTU picking method could effectively reduce the final OTU numbers by firstly clustering against reference sequences, picking up sequences clustering around references as centroids with 0.97 similarity, then, re-clustering remaining sequences which could not be assigned to reference OTUs by de novo method. Singletons were filtered out to exclude potential sequencing errors. Taxonomy assignment was conducted by BLAST method, applying QIIME compatible SILVA 119 SSURef database as the reference (newly defined archaeal taxa were manually added and recurated). The matrix file "biom" was made by adding the taxonomic referring information into OTU table. Archaeal "biom" file was made by exclusively filtering non-archaeal sequences from OTU table obtained from archaeal 16S rRNA gene MiSeq sequencing libraries. Similarly, bacterial "biom" file was made from microbial 16S rRNA gene MiSeq sequencing libraries by filtering non-bacterial sequences. Microbial "biom" file was made without any filtering. Table 


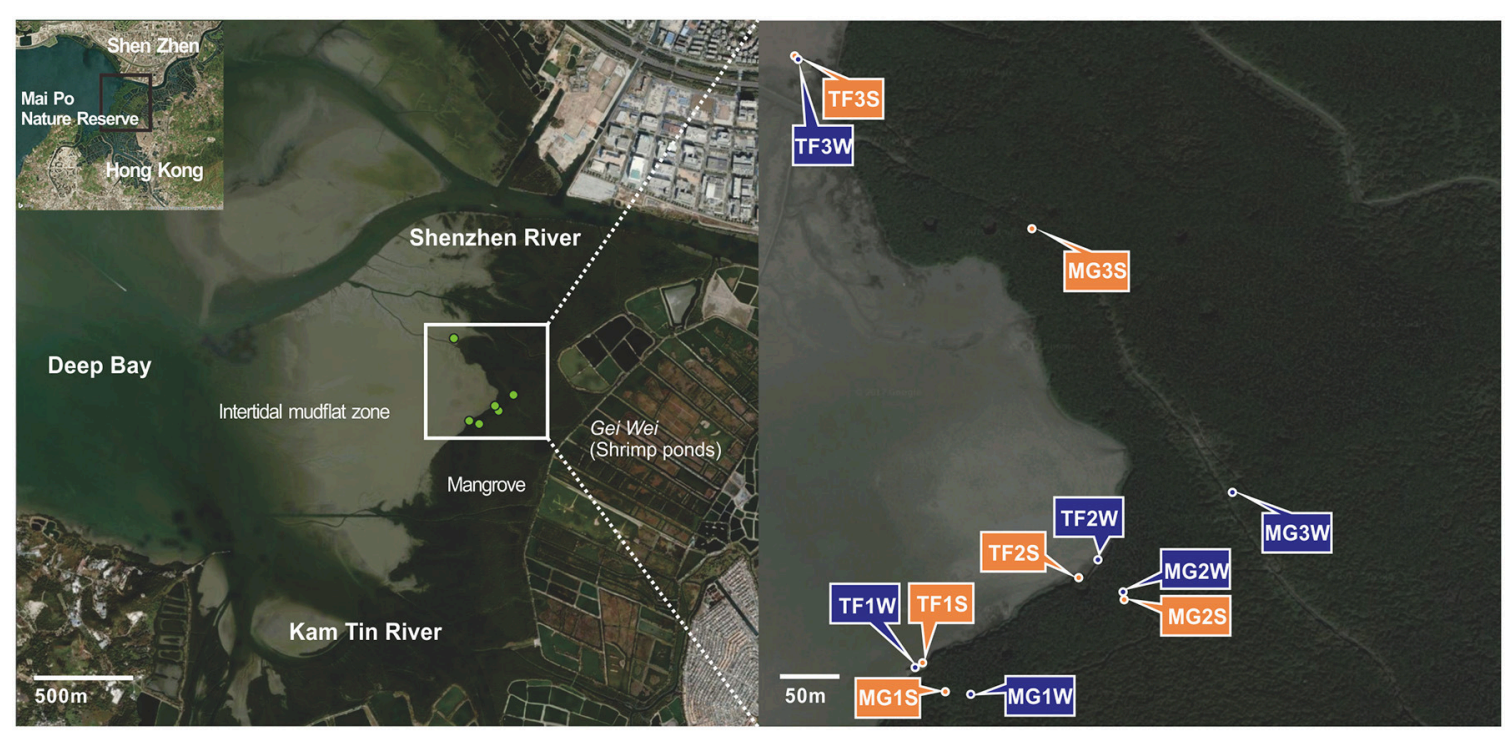

FIGURE 1 | Satellite map depicting Mai Po area and sampling locations based on ArcGIS with Bing Aerial layout and Google Map.

summary information including the sequence numbers in each library could be reflected by "summarize-table" command. The smallest library's size number was used to subsample all libraries by using "multiple_rarefactions_even_depth.py" command. Compositional profiles based on taxonomical information were depicted by "summarize_taxa_through_plots.py" using map file to index each library. Aligning was conducted by PyNAST method using "core_Silva119_alignment.fna" from QIIME compatible SILVA 119 SSURef database as the reference with $60 \%$ similarity criterion. Alignment filtering was conducted independently without lanemask file, with entropy threshold as 0.1 and gap filter threshold as 0.9. Phylogenetic tree was constructed by default. Then, alpha diversity calling was conducted with "biom" files after rarefaction. Alpha diversity indices including Shannon, PD whole tree, Chao1, observed species, Good's coverage, and Simpson values were generated accordingly. Beta diversity procedure was conducted by applying both unweighted, weighted UniFrac matrix and non-phylogenetic Bray-Curtis matrix methods.

\section{Diversity and Statistical Analysis}

Stack bar charts for delineating taxonomic profiles of bacterial, archaeal and microbial community of all libraries were originated from QIIME results, and visualized by Origin8 and CorelDraw. Pearson correlation analysis on reflecting the potential correlation relationship between physicochemical parameters and diversity, abundance property of bacterial, archaeal and microbial communities was conducted in GraphPad Prism (Motulsky, 1999). Correlation coefficient matrix was generated by two-tailed $p$-value statistics. Statistical analysis of alpha diversity was conducted in IBM SPSS software by oneway ANOVA (with Dunnett T3 post hoc test) and unpaired t-test (SPSS Inc., Chicago). Mantel Test analysis implemented in QIIME was conducted to analyze the correlation relationship between physicochemical parameters and UniFrac and BrayCurtis distance matrices from beta diversity analysis. Multivariate regression tree (MRT) was constructed using the $\mathrm{R}$ package mvpart, processed by normalized compositional abundance at the class level. The selected trees with 7 -split tree size were depicted to reflect the explanatory effect of environmental variables on the community structures (Oksanen et al., 2007; Therneau et al., 2012). Principal Coordinate Analysis (PCoA) on depicting the dissimilar relationship of samples was conducted in terms of sediment depth and seasonality categories, based on both phylogenetic and non-phylogenetic distance matrix methods. To test whether the distribution of sample plots in PCoA analysis was statistically significant, both of adnois and anosim methods within "compare_categories" command in QIIME were applied. LDA Effect Size (LEfSe) analysis was applied on identifying biomarker taxa, which are significantly associated within certain sample categories (Segata et al., 2011). CANOCO 5.0 was used to conduct Redundancy Analysis (RDA) for depicting the explaining effect of environmental factors on the ordination of samples and their compositional taxa.

\section{Quantification of Abundance of Bacteria and Archaea}

To quantify the 16S rRNA gene copy number of bacteria and archaea in each sample, quantitative PCR measurement and statistical analysis were employed by StepOnePlus RealTime PCR System instrument (Applied Biosystems). Primer pair Arch349F/958R was used to detect the archaeal $16 \mathrm{~S}$ rRNA gene with annealing temperature of $52^{\circ} \mathrm{C}$, primer pair Bac331F/Bac797R was used to detect the bacterial 16S rRNA gene with annealing temperature of $50^{\circ} \mathrm{C}$ (Nadkarni et al., 2002). The rest denaturing and elongation time and temperature were set according to the manufacturer's instruction. The $15 \mu \mathrm{l} \mathrm{qPCR}$ 
TABLE 1 | Physicochemical parameters of samples collected from Mai Po Nature Reserve.

\begin{tabular}{|c|c|c|c|c|c|c|c|c|c|}
\hline Samples & Sampling position & $\begin{array}{l}\text { Depth } \\
\text { (cm) }\end{array}$ & $\mathrm{pH}$ & $\begin{array}{c}\text { Redox } \\
\text { (mV) }\end{array}$ & $\begin{array}{c}\text { Water } \\
\text { content (\%) }\end{array}$ & $\begin{array}{c}\mathrm{NH}_{4}^{+} \\
\text {( } \mu \mathrm{mol} / \mathrm{kg} \\
\text { dry soil) }\end{array}$ & $\begin{array}{c}\mathrm{NO}_{2}^{-} \\
(\mu \mathrm{mol} / \mathrm{kg} \\
\text { dry soil) }\end{array}$ & $\begin{array}{c}\mathrm{NO}_{2}^{-}+\mathrm{NO}_{3}^{-} \\
(\mu \mathrm{mol} / \mathrm{kg} \\
\text { dry soil) }\end{array}$ & $\begin{array}{c}\text { Organic } \\
\text { matters } \\
(\%)\end{array}$ \\
\hline MG1WinA & $22^{\circ} 29.665^{\prime} \mathrm{N}, 114^{\circ} 01.742^{\prime} \mathrm{E}$ & $0-2$ & 7.07 & 300 & 70.7 & 57.26 & 2.08 & 106.29 & 11.2 \\
\hline MG1WinB & & $10-15$ & 6.38 & 296 & 58.9 & 91.28 & 1.05 & 3.86 & 13.3 \\
\hline MG1WinC & & 20-25 & 7.21 & 251 & 58.6 & 141.02 & 0.53 & 1.56 & 22.9 \\
\hline MG1WinD & & $40-45$ & 7.60 & 219 & 59.4 & 95.87 & 0.57 & 1.36 & 12.3 \\
\hline MG2WinA & $22^{\circ} 29.709^{\prime} \mathrm{N}, 114^{\circ} 01.812^{\prime} \mathrm{E}$ & $0-2$ & 7.11 & 264 & 55.6 & 29.60 & 0.63 & 15.82 & 11.2 \\
\hline MG2WinB & & $10-15$ & 6.41 & 259 & 54.8 & 27.03 & trace & 1.37 & 11.1 \\
\hline MG2WinC & & $20-25$ & 6.84 & 235 & 56.4 & 58.97 & 0.14 & 1.12 & 10.6 \\
\hline MG2WinD & & $40-45$ & 7.13 & 217 & 52.6 & 51.98 & 0.21 & 0.82 & 10.1 \\
\hline MG3WinA & $22^{\circ} 29.762^{\prime} \mathrm{N}, 114^{\circ} 01.866^{\prime} \mathrm{E}$ & $0-2$ & 6.41 & 266 & 54.0 & 14.68 & trace & 8.81 & 11.2 \\
\hline MG3WinB & & $10-15$ & 6.27 & 209 & 57.0 & 142.83 & trace & 0.49 & 12.7 \\
\hline MG3WinC & & 20-25 & 6.79 & 202 & 51.4 & 156.43 & trace & 1.36 & 10.8 \\
\hline MG3WinD & & $40-45$ & 7.40 & 209 & 50.4 & 78.16 & 0.12 & 0.41 & 9.7 \\
\hline TF1WinA & $22^{\circ} 29.676^{\prime} \mathrm{N}, 114^{\circ} 01.706^{\prime} \mathrm{E}$ & $0-5$ & 7.06 & 217 & 56.2 & 55.55 & 4.43 & 23.53 & 10.0 \\
\hline TF1WinB & & $13-16$ & 7.68 & 212 & 55.2 & 312.56 & 1.58 & 3.72 & 8.2 \\
\hline TF2WinA & $22^{\circ} 29.726^{\prime} \mathrm{N}, 114^{\circ} 01.799^{\prime} \mathrm{E}$ & $0-5$ & 7.45 & -63.6 & 69.8 & 15.84 & 2.19 & 5.50 & 12.1 \\
\hline TF2WinB & & $13-16$ & 7.77 & 58 & 58.8 & 214.46 & 1.87 & 2.56 & 9.6 \\
\hline TF3WinA & $22^{\circ} 29.951^{\prime} \mathrm{N}, 114^{\circ} 01.651^{\prime} \mathrm{E}$ & $0-5$ & 7.02 & -42.8 & 65.0 & 7.10 & 1.01 & 6.24 & 10.1 \\
\hline TF3WinB & & $13-16$ & 7.52 & 106.6 & 57.2 & 250.75 & 1.32 & 2.25 & 8.5 \\
\hline MG1SumA & $22^{\circ} 29.665^{\prime} \mathrm{N}, 114^{\circ} 01.726^{\prime} \mathrm{E}$ & $0-2$ & 6.68 & 398 & 62.0 & 127.41 & 1.22 & 14.67 & 14.5 \\
\hline MG1SumB & & $10-15$ & 7.58 & 171 & 57.5 & 348.06 & 1.20 & 7.13 & 13.1 \\
\hline MG1SumC & & $20-25$ & 7.90 & 95 & 53.0 & 307.89 & 0.88 & 6.38 & 11.4 \\
\hline MG2SumA & $22^{\circ} 29.704^{\prime} \mathrm{N}, 114^{\circ} 01.814^{\prime} \mathrm{E}$ & $0-2$ & 5.82 & 348 & 53.6 & 25.52 & 0.50 & 18.56 & 10.7 \\
\hline MG2SumB & & $10-15$ & 6.87 & 291 & 51.4 & 22.21 & 0.73 & 9.13 & 14.4 \\
\hline MG2SumC & & $20-25$ & 6.84 & 244 & 57.3 & 20.93 & 0.74 & 7.89 & 12.6 \\
\hline MG3SumA & $22^{\circ} 29.875^{\prime} \mathrm{N}, 114^{\circ} 01.767^{\prime} \mathrm{E}$ & $0-2$ & 6.60 & 312 & 54.8 & 26.97 & 0.76 & 22.25 & 12.8 \\
\hline MG3SumB & & $10-15$ & 7.31 & 298 & 52.4 & 15.96 & 1.75 & 11.19 & 12.9 \\
\hline MG3SumC & & $20-25$ & 7.32 & 241 & 46.4 & 22.41 & 0.50 & 9.10 & 11.1 \\
\hline TF1SumA & $22^{\circ} 29.679^{\prime} \mathrm{N}, 114^{\circ} 01.709^{\prime} \mathrm{E}$ & $0-5$ & 7.10 & 80 & 61.8 & 107.74 & 2.82 & 27.03 & 10.0 \\
\hline TF1SumB & & $13-16$ & 7.86 & 179 & 54.8 & 262.91 & 0.85 & 7.43 & 8.9 \\
\hline TF2SumA & $22^{\circ} 29.718^{\prime} \mathrm{N}, 114^{\circ} 01.786^{\prime} \mathrm{E}$ & $0-5$ & 7.38 & -35 & 66.4 & 187.17 & 6.60 & 43.17 & 10.5 \\
\hline TF2SumB & & $13-16$ & 8.17 & 65 & 55.8 & 368.63 & 0.83 & 4.39 & 9.7 \\
\hline TF3SumA & $22^{\circ} 29.949^{\prime} \mathrm{N}, 114^{\circ} 01.656^{\prime} \mathrm{E}$ & $0-5$ & 7.31 & 111 & 60.1 & 127.18 & 2.64 & 22.81 & 10.3 \\
\hline TF3SumB & & $13-16$ & 7.81 & 170 & 56.3 & 334.54 & 2.00 & 9.84 & 8.1 \\
\hline
\end{tabular}

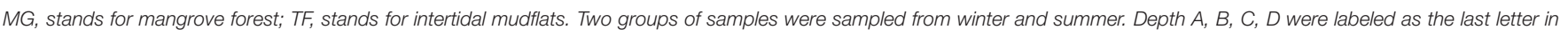
sample names from surface to subsurface layers.

system contained the following reagents: $1 \mu \mathrm{l}$ of DNA template (10-fold-diluted to avoid interference of humic acids), $7.5 \mu \mathrm{l}$ of Premix (FastStart Universal SYBR Green Master, Roche), $12 \mu \mathrm{g}$ of BSA (100 mg/ml, Roche), $0.375 \mu \mathrm{l}$ of forward and reverse primer $(20 \mu \mathrm{M})$ for archaeal qPCR, alternatively $0.15 \mu \mathrm{l}$ of forward and reverse primer $(20 \mu \mathrm{M})$ for bacterial qPCR and $\mathrm{ddH}_{2} \mathrm{O}$ (make up final volume to $15 \mu \mathrm{l}$ ).

One positive ligated plasmid of PMD-18T with gene fragments from previously prepared PCR products was used to make the successive 10 -fold dilution series for generating standard curves for archaeal and bacterial qPCR. Copy numbers of standard plasmid dilution were calculated by firstly measuring the DNA concentration by Nanodrop and then applied into the equation: Abundance of gene copy number/ $\mu l=($ amount $/ \mu l$ $\left.\times 6.022 \times 10^{23}\right) /\left(\right.$ length $\left.\times 1 \times 10^{9} \times 660\right)$. Results deviated unreasonably from values in the replicate groups were omitted and undetermined results were deleted. Final adjusted standard curve properties were as following, archaea: $r^{2}=0.998-$ 0.999, Eff $\%=64.447-69.356$; bacteria: $r^{2}=0.994-0.997$, $\mathrm{Eff} \%=91.226-92.464$.

\section{Sequencing Result Deposition}

Raw MiSeq sequencing data for 33 archaeal 16S rRNA gene libraries from Mai Po wetland were deposited in EMBL-EBI ENA database with accession no. PRJEB12429. Raw MiSeq sequencing data for 33 microbial 16S rRNA gene libraries from Mai Po wetland were deposited in EMBL-EBI ENA database with accession no. PRJEB12432. 


\section{RESULTS}

\section{Physicochemical Properties of Sediment Samples in Winter and Summer}

Generally, patterns of different physicochemical properties of sediment depth profile of each sampling site were determined for sediment types at different seasons (Table 1). In winter samples, sediments of B layer at mangrove forest (MG) had the lowest $\mathrm{pH}$ values, and the redox potential and water content values generally showed a decreasing trend along the increase of sediment depth. The $\mathrm{C}$ layer of sediments showed the highest concentration of $\mathrm{NH}_{4}^{+}$, and the upper layers (A and B layers) tended to acquire higher $\mathrm{NO}_{2}^{-}, \Sigma\left(\mathrm{NO}_{3}^{-}+\mathrm{NO}_{2}^{-}\right)$concentration and organic matter content than the corresponding lower layers (D layers), except for the organic matter content value of MG1WinC, which was considerably higher than the others. In winter intertidal mudflat (TF) samples, $\mathrm{pH}$, redox potential and $\mathrm{NH}_{4}^{+}$were lower in the surface layers than in the subsurface layers. While, in terms of water content, $\mathrm{NO}_{2}^{-}, \Sigma\left(\mathrm{NO}_{3}^{-}+\mathrm{NO}_{2}^{-}\right)$, and organic matter content, higher values were observed in the surface layers than that in subsurface, with a few exceptions, such as redox potential values of TF1WinA and TF1WinB pair, and $\mathrm{NO}_{2}^{-}$of TF3WinA and TF3WinB pair. In summer MG samples, $\mathrm{pH}$ value showed a clear increasing trend along the increase of sediment depth, while a decreasing trend for redox potential value, water content and $\Sigma\left(\mathrm{NO}_{3}^{-}+\mathrm{NO}_{2}^{-}\right)$was found, except for the water content of MG2SumC sample. The $\mathrm{NH}_{4}^{+}$of samples from MG site 1 depth profile showed a considerable elevation than the site 2 and 3. In summer TF samples, patterns of depth profile at individual sampling sites were identical with those of winter TF samples. In addition, value ranges of all the parameters of summer TF samples were also close to those of winter TF samples.

\section{Abundance of Archaea and Bacteria}

Quantitative measurement of bacterial and archaeal community abundance was based on the 16S rRNA gene abundance (Figure 2, Supplementary Table S1). The bacterial community abundance of MG sediments showed a clear decreasing tendency from the surface layers down to the subsurface layers at all three sampling sites, in both winter and summer. A similar phenomenon was also evident that bacterial abundances in surface layers were always higher than the corresponding subsurface layers among TF sediment samples, irrespective of sampling sites and seasonality, except for TF1, where both surface and subsurface sediment samples had similar bacterial 16S rRNA gene abundances.

For archaeal community abundance, a different distribution pattern was identified. TF sample groups in winter showed an opposite distribution pattern from bacteria, in that lower archaeal abundance in the surface samples was detected than the corresponding subsurface samples. However, the relative abundance of archaea within the total microbial community quantified by $16 \mathrm{~S}$ rRNA gene copy numbers represented a consistent trend opposite of the variation of bacterial community abundance in sediment depth profiles. Regardless of sampling sites, sediment types and seasons, the abundance of archaea always increased with the sediment depth, ranging from the lowest $0.19 \%$ (TF1WinA) to the highest $8.63 \%$ (MG2WinD) of the total microbial community.

The observed bacterial $16 \mathrm{~S}$ rRNA gene abundance ranged from $9.6 \times 10^{8}$ to $2.97 \times 10^{10}$ and $2.02 \times 10^{9}$ to $4.78 \times 10^{10}$ gene copies/gram dry sediment in winter and summer, while the observed archaeal 16S rRNA gene abundance ranged from $1.96 \times$ $10^{7}$ to $3.62 \times 10^{8}$ and $9.17 \times 10^{7}$ to $3.72 \times 10^{10}$ gene copies/gram dry sediment in winter and summer, respectively. Although the range of $16 \mathrm{~S}$ rRNA gene abundance was wider in summer than in winter, there was no significant difference in either bacterial or archaeal 16S rRNA gene abundance between summer and winter based on unpaired $t$-test $(p>0.05)$. Detailed statistical results of bacterial and archaeal 16S rRNA gene abundance are listed in Supplementary Table S1.

\section{Compositional Summary of Bacterial and Archaeal Community}

The composition of bacterial communities of 33 sediment samples from Mai Po wetland was shown in Figure 3A. The bar chart of taxonomic composition is shown for the phylum level bacterial taxa abundance, represented by average abundance among all samples $>0.5 \%$. The most abundant five bacterial phyla are: Proteobacteria (45.6\%), Chloroflexi (14.7\%), Bacteroidetes (12.0\%), Cyanobacteria (7.6\%), and Planctomycetes (4.5\%) (Supplementary Table S2). In terms of different sediment types, the most abundant five phyla ranking remained stable. Among the subgroups of Proteobacteria, Deltaproteobacteria (21.9\%) and Gammaproteobacteria (15.0\%) were the most abundant components, while Betaproteobacteria, Epsilonproteobacteria, and Alphaproteobacteria were minor groups, contributing a small proportion $(2.7,2.7$ and $2.6 \%)$ in the total bacterial community. For the second most abundant phylum, Chloroflexi, it was mainly comprised of two classes: Anaerolineae (9.1\%) and Dehalococcoidia (4.4\%). Bacteroidetes was composed of Flavobacteriia (4.4\%), Cytophagia (1.8\%), Sphingobacteriia (1.3\%), BD2-2 (1.2\%), SB-1 (0.7\%), and SB$5(0.7 \%)$. While Cyanobacteria was mainly represented by the subordinate class Chloroplast $(7.5 \%)$, Planctomycetes was mainly represented by the subordinate class Phycisphaerae $(2.3 \%)$ and Planctomycetacia (1.1\%). Furthermore, Cyanobacteria was regularly enriched in the surface sediments, irrespective of sediment types, but mainly represented in winter samples. Bacteroidetes and Chloroflexi showed an opposite distribution pattern for their relative abundances in the surface and subsurface layers, regardless of sediment types and seasons. Bacteroidetes abundance fraction decreased along the sediment depth at the individual sampling site, while Chloroflexi abundance fraction increased along the sediment depth at the individual sampling site.

The composition of archaeal communities of 33 sediment samples from Mai Po wetland was shown in Figure 3B. The bar chart of archaeal community composition was represented by taxa abundance at the class level with an average abundance $>0.1 \%$. The most abundant five classes among all the archaeal communities were Thermoplasmata (34.2\%), Bathyarchaeota Subgroup 6 (20.1\%), and Subgroup 8 (16.8\%), Marine Group 

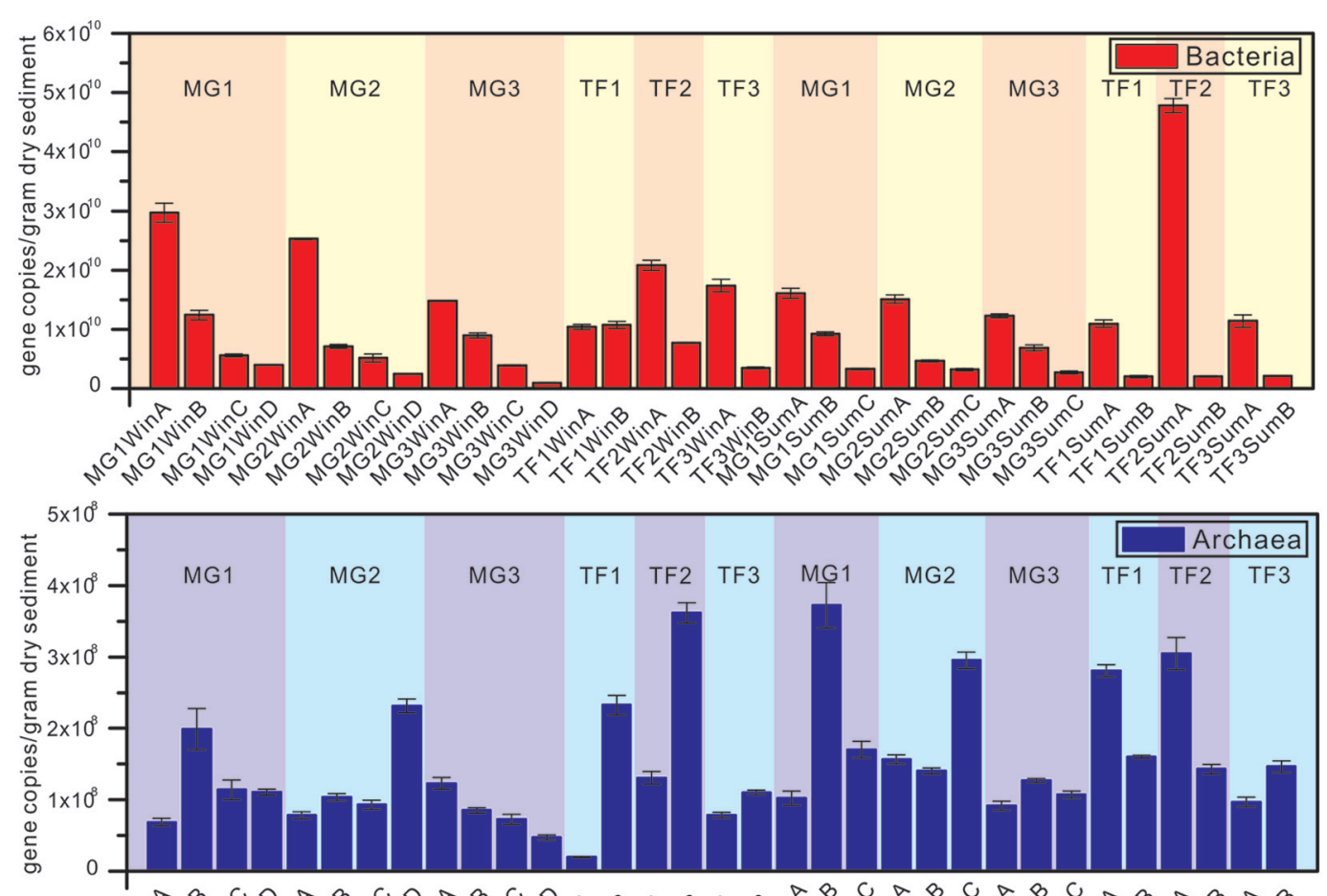

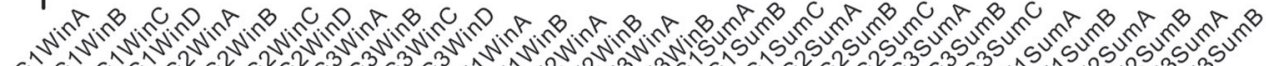

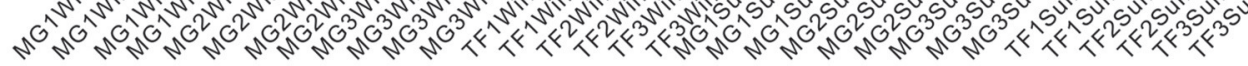

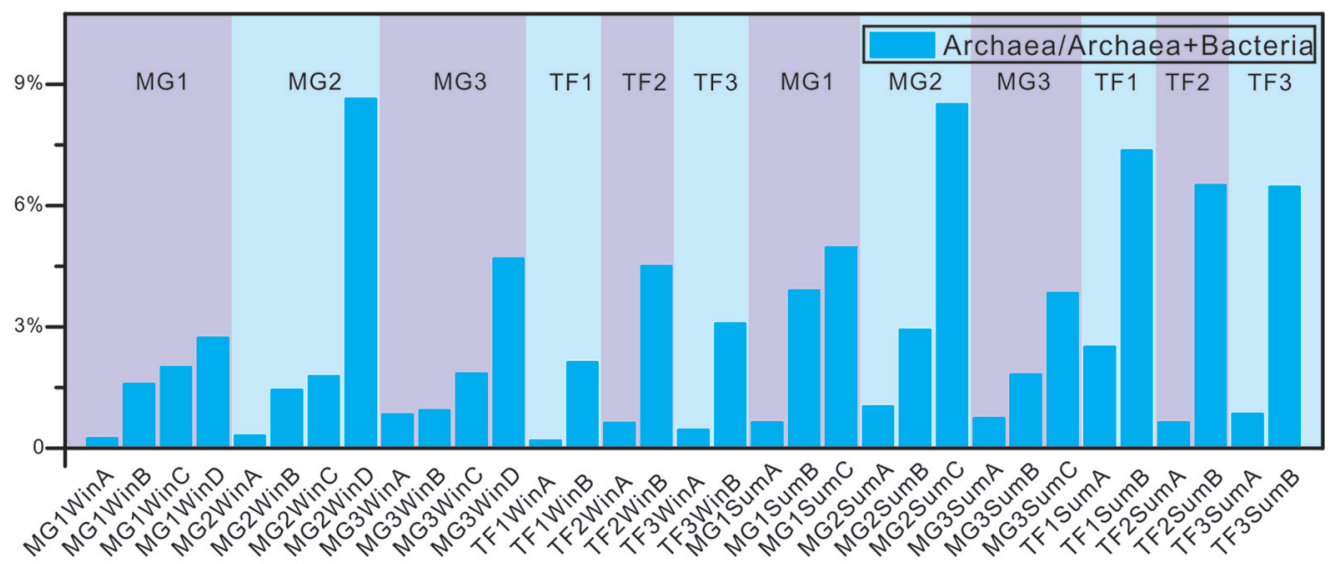

FIGURE 2 | Quantitative PCR results on the abundance of bacterial and archaeal 16S rRNA genes of sediment samples from mangrove forest (MG) and intertidal mudflat (TF). The ratio of archaeal 16S rRNA genes over total archaeal and bacterial 16S rRNA genes reflects the archaeal fraction in the total microbial community. The unit of vertical axis is copy numbers/gram dry sediments.

I (10.5\%) and Marine Benthic Group B (MBG-B) $(8.4 \%)$ (Supplementary Table S3). They occupied almost $90 \%$ of the average abundance in the total archaeal community. There were still other Bathyarchaeota subgroups, such as Subgroup 1, 5b, 10, 11, 13, 15/C3, 17, and the ungrouped Bathyarchaeota. The total Bathyarchaeota contributed to as high as $41.8 \%$ of the average abundance in the total archaeal community. The other uncultured group of Crenarchaeota, Marine Benthic Group A (MBG-A), could only account for $0.3 \%$ of the average abundance of the total archaeal community. For the methanogenic Euryarchaeota class, Methanomicrobia and Methanococci accounted for $2.6 \%$ of the average abundance of the total archaeal community. MBG-B showed a regular distribution pattern of their abundances, increasing along the sediment depth at the individual sampling site, irrespective of sediment types and seasons. Moreover, Marine Group I (Thaumarchaeota) only showed their considerably higher proportion in surface samples than the corresponding subsurface samples at the individual sampling site, yet their contribution among surface samples could also vary greatly, ranging from as low as $1.1 \%$ in TF1SumA to as high as $87.8 \%$ in MG3SumA. Similarly, the order of the most abundant five classes remained unchanged, in terms of two sediment types. 


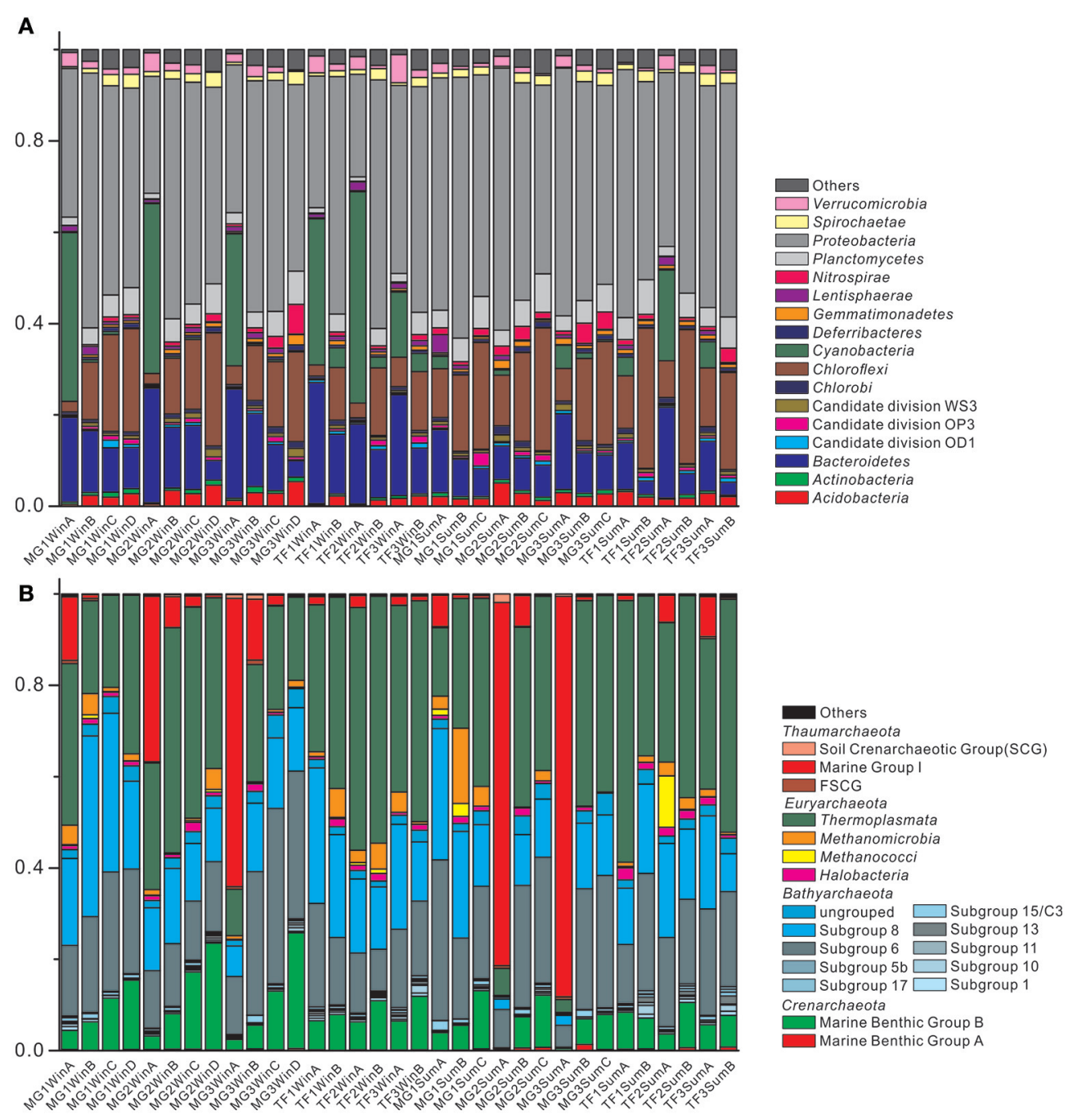

FIGURE 3 | Bar chart of taxonomic profiles of (A) bacterial community at phylum level with abundance $>0.5 \%$, and (B) archaeal community at class level with abundance $>0.1 \%$. The remaining groups with lower abundance are classified into "Others."

\section{Alpha Diversity of Bacterial, Archaeal, and Microbial Communities}

Through alpha processing pipeline by QIIME software, alpha diversity indices, including PD whole tree, Chao1, Good's coverage, observed species, Shannon and Simpson indices, were calculated for individual bacterial, archaeal and microbial communities (Supplementary Table S4). The Good's coverage of bacterial, archaeal and microbial communities ranged within $66.1-84,90.3-98.2$, and $67.6-83.4 \%$, respectively. The rarefaction curves of the above three communities indicated that the Good's coverage values of all samples achieved the plateau (data not shown), and further increasing of sequencing efforts will not significantly elevate the Good's coverage values. The statistical comparisons of these alpha diversity indices among sediment samples classified by layer depth, seasonality, sediment type and sampling site to find any significant differences of certain alpha diversity indices between each pair of sample categories or significant intergroup differences among all of the samples were conducted. It was revealed that, for all the bacterial communities, there were significant differences among the layer depth categories in terms of observed species, Shannon and Simpson indices. Depth A samples (the lowest layer) had the lowest value of the above alpha diversity indices. The unpaired $t$ test showed that the Shannon index in winter samples was lower than that in summer, for all the bacterial communities $(p<0.05)$. For archaeal communities, winter samples had higher Chaol and observed species indices and lower Good's coverage value than those of summer $(p<0.05)$. Moreover, samples of intertidal mudflats had higher Simpson index than those of mangrove forest $(p<0.05)$, and higher PD whole tree, Chao1, observed species and Shannon indices and lower Good's coverage value than those of mangrove forest $(p<0.001)$. For the total bacterial and archaeal communities, there were significant differences among the four layer depths for the alpha diversity, including 
PD whole tree, Good's coverage, observed species, Shannon and Simpson indices. And the samples with the lowest layer depth (Depth A) had the lowest PD whole tree, observed species, Shannon and Simpson indices and highest Good's coverage values among these four categories $(p<0.05)$. The Simpson index of winter samples was significantly lower than that of summer samples $(p<0.05)$. Detailed comparison results of alpha diversity indices among different categorical divides are summarized in the Supplementary Table S4.

\section{Relationship of Community Properties and Physicochemical Parameters}

In terms of the relationship between alpha diversity indices and physicochemical parameters, Shannon and Simpson indices of bacterial communities were positively correlated with sediment layer depth and negatively correlated with water content by the Pearson correlation analysis, with statistical support $(p<0.05)$ (Table 2). The observed species of bacterial communities were negatively correlated with $\Sigma\left(\mathrm{NO}_{3}^{-}+\mathrm{NO}_{2}^{-}\right)(p<0.05)$.

For archaeal communities, $\mathrm{pH}$ was positively correlated with alpha diversity indices, including PD whole tree, Chao1, observed species, Shannon and Simpson indices, but negatively correlated with Good's coverage with statistical support; however, the correlation relationship between redox potential and these indices was the opposite trend. Moreover, $\mathrm{NH}_{4}^{+}$was positively correlated with Shannon and Simpson indices of archaeal community $(p<0.05)$, but organic matter content was negatively correlated with alpha diversity indices, including PD whole tree, Chaol and observed species, and positively correlated with Good's coverage value ( $p<0.01$; Table 2$)$.

Principal Coordinate Analysis (PCoA) on depicting the dissimilar relationship of samples revealed that, in terms of sediment types, there were clear separations between these two categorical assemblages (sediment depths and sediment types) in both bacterial and archaeal community analyses (Figure 4). These patterns were further evidenced by statistical analyses of the distribution of community coordinates. Based on both the unweighted UniFrac and non-phylogenetic Bray-Curtis distance matrix method, it was also significant to differentiate these two categorical assemblages (sediment depths and sediment types) (Supplementary Table S5). In terms of the four layer depths, the differentiation patterns among these four categories in both bacterial and archaeal communities were significant by all distance matrix methods, especially for bacterial communities ( $p<0.001$; Figure 4, Supplementary Table S5). The other two categories (seasons and sampling sites) were also checked for identifying any influence on the beta diversity pattern of bacterial and archaeal communities. Seasonality could be influential on the beta diversity pattern of bacterial communities based on weighted UniFrac and Bray-Curtis distance matrix method, sampling sites could be influential on the beta diversity pattern of archaeal communities based on unweighted UniFrac and Bray-Curtis distance matrix method (Supplementary Table S5). Regarding to the total microbial communities, influences on their beta diversity pattern imposed by the four types of category were similar to those of bacterial communities.
Mantel Test was applied to delineate the correlation relationship between UniFrac and Bray-Curtis matrices of community composition and the distance matrix of physicochemical parameters (Supplementary Table S6). Layer depth, water content, $\mathrm{NO}_{3}^{-}$and $\Sigma\left(\mathrm{NO}_{3}^{-}+\mathrm{NO}_{2}^{-}\right)$ were significantly correlated with bacterial community dissimilar distance matrix by both UniFrac and Bray-Curtis matrix method $(p<0.05)$. Redox potential was significantly correlated with bacterial community dissimilar distance matrix only by unweighted UniFrac and Bray-Curtis matrix method $(p<0.05)$. The $\mathrm{pH}$ was significantly correlated with bacterial community dissimilar distance matrix only by unweighted UniFrac matrix method $(p<0.05)$. However, only $\mathrm{pH}$ was significantly correlated with archaeal community dissimilar distance matrices by both UniFrac and Bray-Curtis matrix method $(p<0.01)$. Redox potential was significantly correlated with archaeal community dissimilar distance matrix only by unweighted UniFrac matrix method $(p<0.05)$.

As shown in the MRT (Figure 5A), sediment depth could account for $46.4 \%$ of the explained variance among all bacterial communities. The most discriminated groups under this splitting point were Chloroplast (Cyanobacteria) and Deltaproteobacteria, accounting for 43.64 and $27.13 \%$ of the explained deviance. Then, seasonality played a minor role in splitting the bacterial communities of surface layer sediments (Depth $<6.75 \mathrm{~cm}$ ) into two branches, accounting for $26.04 \%$ of the total explained variance. The organic matter and water content could further divide the following winter and summer branches into four parts, with relatively small explaining effects. For the subsurface layer sediments (Depth $\geq 6.75 \mathrm{~cm}), \Sigma\left(\mathrm{NO}_{3}^{-}+\mathrm{NO}_{2}^{-}\right)$could split the branch into two parts, one with the value higher than $7.28 \mu \mathrm{mol} / \mathrm{kg}$ dry soil, and the other with value smaller than $7.28 \mu \mathrm{mol} / \mathrm{kg}$ dry soil. Subsequently, the latter one could be further divided into two branches, including sediments from the deepest layer (Depth D), and the other above Depth D. The overall contribution of environmental variables on explaining the variance of whole bacterial communities was $82.5 \%$.

In terms of the archaeal communities (Figure 5B), $\mathrm{pH}$ value could divide the MRT into two major branches, one contained samples with acidic $\mathrm{pH}$ condition, and the other one with $\mathrm{pH}$ value over than 6.64, which accounts for $27.57 \%$ of the explained variance. The most discriminated groups under this splitting point were Thermoplasmata and Marine Group I (Thaumarchaeota), accounting for 33.38 and $56.54 \%$ of the explained deviance. The former branch could be further divided into two by depth with the explaining effect of $25.74 \%$. For the branch with $\mathrm{pH}$ higher than 6.64, five branches were formed by organic matters, $\mathrm{NO}_{2}^{-}$and $\mathrm{NO}_{3}^{-}$subsequently with decreasing explaining effects. The total contribution of environmental variables on explaining the variance of the whole archaeal communities was $76.9 \%$.

\section{Differentiated Distribution of Bacterial and Archaeal Communities}

As revealed by LEfSe analysis diagram for the depth layer (Figure 6A), bacterial taxa were differently enriched in each 


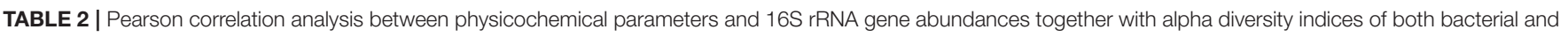
archaeal communities.

\begin{tabular}{|c|c|c|c|c|c|c|c|c|c|}
\hline & Depth & $\mathrm{pH}$ & Redox & $\begin{array}{l}\text { Water } \\
\text { content }\end{array}$ & Ammonium & Nitrite & Nitrate & Nitrate+ Nitrite & $\begin{array}{l}\text { Organic } \\
\text { matters }\end{array}$ \\
\hline \multicolumn{10}{|l|}{ GENE ABUNDANCE } \\
\hline Bacterial 16S rRNA gene & $-0.611^{\star \star \star}$ & -0.190 & -0.207 & $0.667^{\star \star \star}$ & -0.200 & $0.626^{\star \star \star}$ & $0.608^{\star \star \star}$ & $0.633^{\star \star \star}$ & 0.005 \\
\hline \multicolumn{10}{|c|}{ ALPHA DIVERSITY (BACTERIA) } \\
\hline PD whole tree & 0.223 & -0.060 & 0.111 & -0.295 & 0.254 & -0.203 & -0.328 & -0.332 & 0.036 \\
\hline Chao1 & 0.129 & -0.101 & 0.035 & -0.149 & 0.196 & -0.100 & -0.262 & -0.261 & 0.003 \\
\hline Good's coverage & -0.233 & 0.101 & -0.127 & 0.274 & -0.234 & 0.232 & 0.318 & 0.324 & -0.049 \\
\hline observed species & 0.325 & -0.117 & 0.204 & $-0.366^{\star}$ & 0.220 & -0.301 & -0.344 & $-0.354^{*}$ & 0.088 \\
\hline Shannon & $0.399^{*}$ & -0.112 & 0.259 & $-0.419^{\star}$ & 0.208 & -0.330 & -0.309 & -0.323 & 0.106 \\
\hline Simpson & $0.371^{*}$ & -0.065 & 0.249 & $-0.390^{\star}$ & 0.245 & -0.273 & -0.192 & -0.205 & 0.076 \\
\hline \multicolumn{10}{|l|}{ GENE ABUNDANCE } \\
\hline Archaeal 16S rRNA gene & 0.024 & 0.249 & -0.290 & 0.125 & $0.386^{\star}$ & 0.269 & -0.092 & -0.070 & -0.067 \\
\hline \multicolumn{10}{|c|}{ ALPHA DIVERSITY (ARCHAEA) } \\
\hline PD whole tree & 0.021 & $0.516^{\star \star}$ & $-0.648^{\star \star \star}$ & 0.329 & 0.326 & 0.317 & -0.081 & -0.057 & $-0.445^{\star \star}$ \\
\hline Chao1 & 0.008 & $0.432^{*}$ & $-0.611^{\star \star \star}$ & 0.213 & 0.201 & 0.244 & -0.100 & -0.080 & $-0.506^{\star \star}$ \\
\hline Good's coverage & -0.006 & $-0.453^{\star *}$ & $0.642^{\star \star \star}$ & -0.243 & -0.221 & -0.271 & 0.120 & 0.097 & $0.496^{\star \star}$ \\
\hline Observed species & 0.026 & $0.477^{\star \star}$ & $-0.634^{\star \star \star}$ & 0.280 & 0.249 & 0.292 & -0.103 & -0.079 & $-0.471^{\star \star}$ \\
\hline Shannon & 0.148 & $0.509^{\star \star}$ & $-0.534^{\star \star}$ & 0.327 & $0.369^{\star}$ & 0.244 & -0.047 & -0.028 & -0.334 \\
\hline Simpson & 0.221 & $0.425^{\star}$ & $-0.409^{\star}$ & 0.287 & $0.362^{\star}$ & 0.177 & -0.068 & -0.053 & -0.165 \\
\hline
\end{tabular}

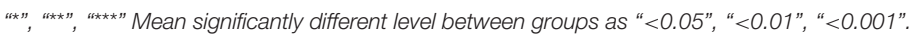
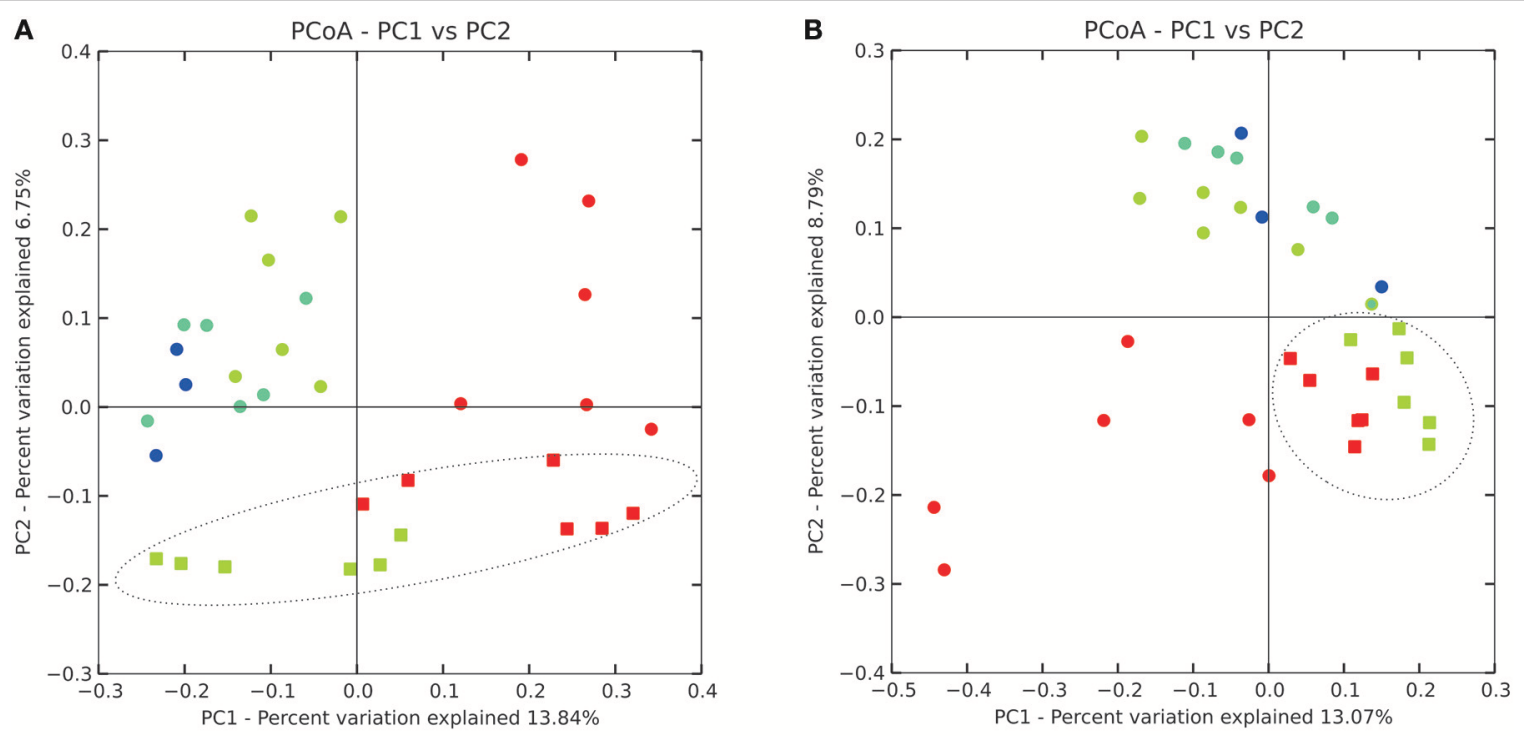

- Depth A - Depth C
- Depth B - Depth D

FIGURE 4 | Principal Coordinate Analysis plots reflecting the dissimilar distance of (A) bacterial community and (B) archaeal community among samples. Dots stand for MG samples, squares stand for TF samples.

layer. Generally, the whole phylum Bacteroidetes, including most of the subordinate classes and orders shown in the diagram, was enriched in Depth A layer, except for Subgroup BD2-2, SB-5 enriched in Depth C layer. Cyanobacteria, Lentisphaerae, Alphaproteobacteria, Verrucomicrobia and their subordinate classes and orders shown in the diagram were enriched in Depth A layer. The order Desulfuromonadales (within Deltaproteobacteria), Alteromonadales, and Oceanospirillales (within Gammaproteobacteria) were also enriched in Depth A layer. Deltaproteobacteria as a whole was enriched in Depth B layer. Besides, Candidate division OP3, Anaerolineae (within Chloroflexi), Anaerolineales (within Anaerolineae), Phycisphaerae 

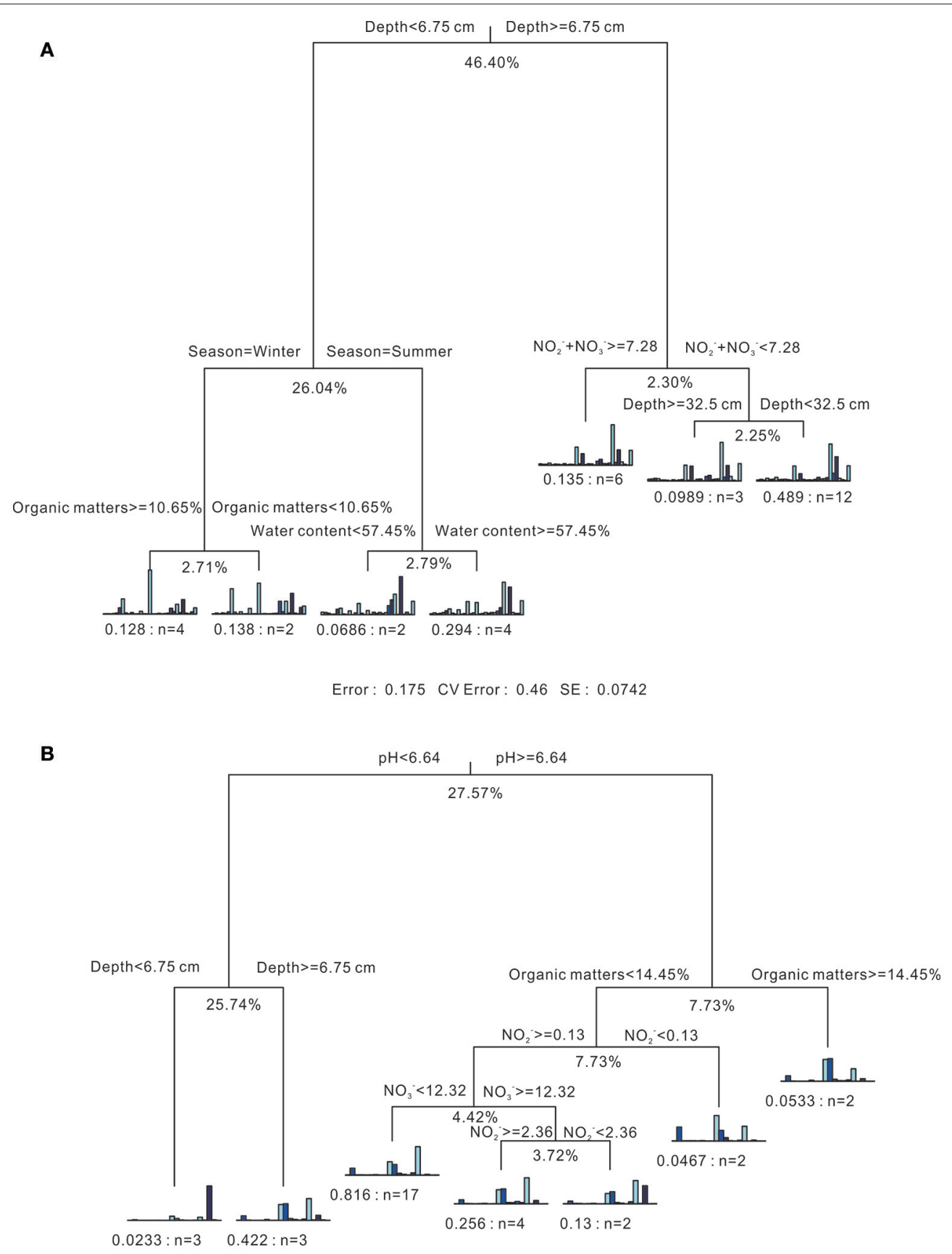

Error: 0.231 CVError: 1.45 SE : 0.33

FIGURE 5 | Multivariate regression tree analysis of the associated relationship of (A) bacterial and (B) archaeal communities and physicochemical parameters. For both figures, 7 -split trees are visualized. Statistics information is listed under individual trees, including the residual error (the reciprocal of the $R^{2}$ of the model), cross-validated error and standard error. Under each branch, a small bar plot is given to represent the normalized abundance of species. The corresponding residual error and sample numbers under each branch are also listed. Values under each split point indicate percentages of variance explained by the split (Complexity $R^{2}$ ). Units for $\mathrm{NH}_{4}^{+}, \mathrm{NO}_{2}^{-}$and $\mathrm{NO}_{3}^{-}$concentrations refer to Table 1.

MSBL9 (within Planctomycetes), Desulfobacterales (within Deltaproteobacteria), Epsilonproteobacteria, Campylobacterales (within Epsilonproteobacteria), and Chromatiales (within Gammaproteobacteria) were enriched in Depth C layer.
Three Acidobacteria subgroups, Subgroup 18, 22 and 23, phylum Chloroflexi as a whole, Dehalococcoidia (within Chloroflexi), Deferribacteres, Nitrospirae, Spirochaetae, and their subordinate orders shown in the diagram were enriched in 


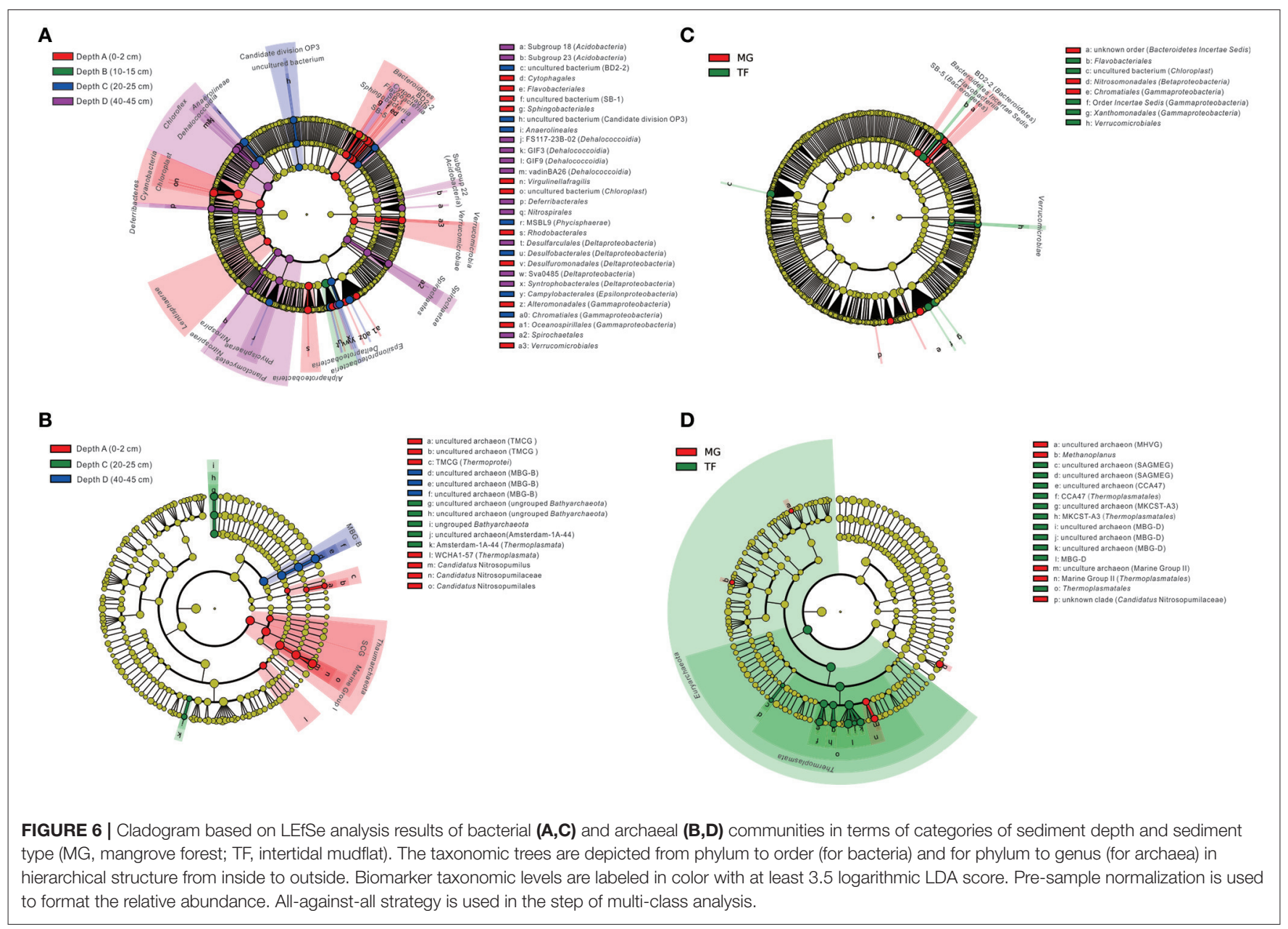

D layer. Planctomycetes as a whole, Phycisphaerae (within Planctomycetes), Desulfarculales, Subgroup Sva048 and Syntrophobacterales (within Deltaproteobacteria) were also enriched in Depth D layer. In terms of differently distributed taxa in two types of sediment samples (Figure 6C), Bacteroidetes Incertae Sedis and Subgroup BD2-2, SB-5, Nitrosomonadales (within Betaproteobacteria) and Chromatiales (within Gammaproteobacteria) were enriched in mangrove covering field sediments, while, Flavobacteriia and order Flavobacteriales (within Bacteroidetes), Chloroplast uncultured bacterium (within Cyanobacteria), order Incertae Sedis and Xanthomonadales (within Gammaproteobacteria), Verrucomicrobiae and order Verrucomicrobiales (within Verrucomicrobia) were enriched in the intertidal mudflat sediments.

For archaeal taxa, Thermoprotei TMCG, Thermoplasmata WCHA1-57 and Thaumarchaeota (including Marine Group I and SCG) and their subordinate orders to genera shown in the diagram were enriched in Depth A layer (Figure 6B). Ungrouped Bathyarchaeota and their subordinate orders to genera shown in the diagram, together with Amsterdam-1A-44 uncultured clone (within Thermoplasmata) were enriched in Depth C layer. Marine Benthic Group B (MBG-B) and its subordinate orders to genera shown in the diagram were enriched in Depth $D$ layer. In terms of the selective distribution of archaeal taxa in each sediment type (Figure 6D), Marine Group II (within Thermoplasmata), uncultured archaeon affiliated to Marine Group II, uncultured archaeon affiliated to Marine Hydrothermal Vent Group (MHVG), Methanoplanus and unknown clade of Candidatus Nitrosopumilaceae were enriched in mangrove forest sediments. While, phylum Euryarchaeota, class Thermoplasmata, order Thermoplasmatales, Thermoplasmatales CCA47, and uncultured archaeon affiliated to Thermoplasmatales CCA47, Marine Benthic Group D (MBG-D), uncultured archaeon affiliated to MBG-D, South African Goldmine Euryarchaeotic Group (SAGMEG) together with its subordinate and MKCST-A3 (within Thermoplasmata) together with its subordinates were enriched in the intertidal mudflat sediments.

\section{DISCUSSION}

\section{Physicochemical Properties of Mai Po Wetland Samples}

According to the rainfall and temperature record from Hong Kong Observatory, the mean temperature and total rainfall for the winter sampling day were $15.5^{\circ} \mathrm{C}$ and trace amount, and those for the summer sampling day were $28^{\circ} \mathrm{C}$ and $32.1 \mathrm{~mm}$, 
respectively. The average values of mean temperature and total daily rainfall of 1 month before the winter sampling day were $16.9^{\circ} \mathrm{C}$ and trace amount and those of the same period before summer sampling day were $29^{\circ} \mathrm{C}$ and $16.6 \mathrm{~mm}$, respectively. According to the in situ temperature measurement in this study, sediments from different layers and sampling sites represented very little variations on the sampling days from the general average temperature.

Nitrate concentration in Pearl River has increased for two to three times over the last three decades and the nitrogen load from Pearl River with seasonal fluctuation is one of the main sources of Hong Kong waters (Lee et al., 2006). The relatively high loading of nutrients and pollutions from discharges of Pearl River and Shenzhen River imposes impacts on Mai Po wetland more in summer than in winter (Lau and Chu, 1999; Lee, 1999; Lee et al., 2006). Mangroves benefit from the nutrient input in summer and their leaf litters will elevate the organic matter level in summer (Tam et al., 1998). The intertidal mudflats surface sediments showed a clear elevation of $\mathrm{NH}_{4}^{+}, \mathrm{NO}_{2}^{-}$and $\Sigma\left(\mathrm{NO}_{3}^{-}\right.$ $+\mathrm{NO}_{2}^{-}$) in summer comparing to those in winter. It might result from the higher nutrient load from adjacent runoffs in summer. Fringe intertidal mudflats are more influenced by the surrounding seawater than the mangrove covering field (Zhou et al., 2010). As for the organic matter content, it might be influenced by the elevation of leaf litters and root materials decomposition in summer, the surface sediments of mangrove covering field tend to acquire higher organic matter contents in summer than in winter (Zhou et al., 2010). In the winter MG sampling sites, the subsurface sediment with depth around $10-15 \mathrm{~cm}$ (Depth B) always showed the lowest $\mathrm{pH}$ value, and along the increase of depth, $\mathrm{pH}$ values tended to increase. In the summer MG sampling sites, $\mathrm{pH}$ values tended to increase along the sediment depth profile for all three layers. As for TF samples, the surface samples always showed lower $\mathrm{pH}$ values than subsurface samples. The redox potential and water content were generally negatively associated for TF samples, and the surface sediments always had lower redox potential than the subsurface sediments. In MG samples, the surface samples showed high water contents, especially for summer samples. Meanwhile, the redox potential values tended to decrease along the sediment depth profile in MG samples, irrespective of seasonality, which might result from the oxygen availability for the upper layers. A reverse trend for redox potential in the upper layers of MG and TF sediments was similar to that reported on the physicochemical assessment of mangrove covering field and unvegetated mudflat sediments in Yifeng Estuary, China (Zhou et al., 2010).

\section{Weaker Seasonal Dynamic of Archaeal Community than Bacterial Community}

There was no significant difference between summer and winter for bacterial and archaeal 16S rRNA gene abundance (Figure 2). The most abundant five bacterial phyla remained unchanged in both seasons, for all bacterial communities (Figure 3A), except for Cyanobacteria, specifically enriched in surface sediments of winter $(p<0.001$; abundance fraction mean difference between summer and winter is $26.2 \%$ ). The most five abundant classes still remained the same, but with minor changes at the order level, for all archaeal communities (Figure 3B). The alpha diversity dynamics between summer and winter showed that Shannon indices of bacterial communities in winter samples were significantly lower than those in summer samples, indicating a less diverse bacterial community distribution pattern in winter (Supplementary Table S4). Chao1 index and observed species for archaeal community in winter were significantly higher than those in summer, indicating more archaeal OTUs and higher archaeal community richness in winter. Seasonality influenced the beta diversity pattern of bacterial community significantly, based on weighted UniFrac and Bray-Curtis distance matrix method but not non-weighted UniFrac distance matrix method, suggesting that both of the presence and the sequence quantity of OTUs from each phylogenetic lineage influenced the distribution pattern of bacterial communities. However, seasonality did not show any significant influence on beta diversity pattern of archaeal community. Overall, seasonality imposed more influence on the beta diversity pattern of bacterial community than archaeal community. O'sullivan et al. (2013) reported that differences of geochemical factors were small between sediment depth profiles at two different seasonal time points with average temperature difference of $8^{\circ} \mathrm{C}$ from Colne estuary, which indicates a weak seasonal influence on the geochemical profiles of coastal wetland sediment. Similarly, weak seasonal dynamics of microbial community in Mai Po wetland sediments could be also attributed to small geochemical profile differences.

\section{Sediment Layer Depth and Seasonality on the Bacterial Community}

Sediment depth positively influenced the bacterial community diversity as reflected by Pearson correlation analysis (Table 2). This phenomenon was also supported by one-way ANOVA analysis, suggesting that diverse indices including Shannon, Simpson and observed species indices were significantly different among four layers, and the Depth A (surface layer) acquired the lowest alpha indices (Supplementary Table S4). For the beta diversity, sediment depth and seasonality also separated microbial communities into corresponding assemblages by PCoA based on UniFrac and Bray-Curtis matrix methods (Figure 4, Supplementary Table S5). Mantel Test was applied to delineate any significant correlation between bacterial community dissimilar distance matrix and physicochemical parameter distance matrix; and results revealed that by at least one distance matrix method (UniFrac and Bray-Curtis matrix method), layer depth, water content, $\mathrm{NO}_{3}^{-}, \Sigma\left(\mathrm{NO}_{3}^{-}+\mathrm{NO}_{2}^{-}\right)$, redox potential and $\mathrm{pH}$ were influential factors, significantly correlated with bacterial community distribution pattern among all the samples (Supplementary Table S6). Furthermore, sediment depth and seasonality were the top two factors accounting for the most explained variance by MRT analysis (Figure 6). Base on the Pearson correlation analysis between the physicochemical parameters and the abundance of bacterial taxa at class level, sediment depth was also the most prevalent influential factor, significantly correlated with the class abundance, either positively or negatively (Supplementary Table S7). Bacterial 16S rRNA 
gene abundance was negatively correlated with sediment depth, but water contents and concentrations of $\mathrm{NO}_{2}^{-}, \mathrm{NO}_{3}^{-}$and $\Sigma\left(\mathrm{NO}_{3}^{-}+\mathrm{NO}_{2}^{-}\right)$were positively correlated (Table 2$)$. Such phenomenon on microbial abundance and community changes influenced by sediment depth has also been reported. Recently, a prokaryotic diversity study on depth profiles along the Colne estuarine gradient from brackish to marine condition revealed that prokaryotic cell numbers also decreased along the sediment depth $(0-50 \mathrm{~cm})$ (O'sullivan et al., 2013). It was also observed that the prokaryotic population shifted between surface and subsurface layers in two estuarine sediment depth profiles, despite of minor changes of geochemical profiles, including methane and sulfate (O'sullivan et al., 2013).

\section{$\mathrm{pH}$ as the Most Influential Factor on Shaping the Archaeal Community}

Pearson correlation analysis between alpha diversity indices and physicochemical parameters showed that $\mathrm{pH}$ was positively correlated with all the diversity and richness indices, but negatively with Good's coverage. In contrast, redox potential showed a reverse trend with $\mathrm{pH}$ value (Table 2 ). $\mathrm{NH}_{4}^{+}$was positively and significantly correlated with archaeal 16S rRNA gene abundance and Shannon and Simpson indices. The organic matter content negatively influenced alpha diversity indices, including, PD tree, Chaol and observed species, and positively influenced the Good's coverage value for all archaeal communities (Table 2). As revealed from the PCoA ordination, sediment depth also imposed significant influence on archaeal communities (Figure 4), while at the same time, archaeal communities along the sediment depth profiles within individual sampling sites also showed significant differences based on weighted UniFrac and Bray-Curtis distance matrix methods (Supplementary Table S5). Moreover, $\mathrm{pH}$ was also the single factor significantly correlated with the archaeal communities by both UniFrac and Bray-Curtis matrix methods based on Mantel Test (Supplementary Table S6). The MRT showed that $\mathrm{pH}$ was one of the most influential factors responsible for $27.57 \%$ of the explaining effect, second by layer depth with $25.74 \%$ (Figure 5B). Similar to this study, another high throughput $16 \mathrm{~S}$ rRNA gene sequencing study on tropical soil archaeal diversity and community at regional level revealed that $\mathrm{pH}$ was the most important factor which partitioned archaeal community distribution at OTU level (Tripathi et al., 2013). Furthermore, non-uniform archaeal abundance response to $\mathrm{pH}$ alteration in an arable soil across a $\mathrm{pH}$ gradient (4.0-8.3) potentially reflected the variation of archaeal community composition along the change of $\mathrm{pH}$ (Bengtson et al., 2012).

\section{Stratified Microbial Distribution}

In delineating the correlation between sediment depth and taxa abundance fraction at the class level, almost all the class abundance fraction either positively or negatively correlated with the increase of sediment layer depth, except for a small portion among all the bacterial classes (ca. 6\%) (Figure 7). The bacterial classes which showed significantly negative correlation with layer depth were also found to be enriched in Depth A layer (Figure 5), meanwhile, the bacterial classes which showed significantly positive correlation with layer depth were also found to be enriched in Depth B, C, D layers (Figure 5). At the same time, as for the archaeal community, Pearson correlation analysis between archaeal class abundance fraction and sediment depth also corroborated the stratified distribution of archaeal communities that revealed by LEfSe analysis (Figure 5). The major phyla and classes of bacteria and archaea discovered in Mai Po wetland were also ubiquitously found in the other natural, constructed wetlands or estuarine sediments (Wang et al., 2012; Jiang et al., 2013; Ansola et al., 2014; Arroyo et al., 2015; Lu et al., 2016).

In this study, a clear stratified distribution of most of the identified taxa at the class level was evident as the abundance fractions of most of the classes (ca. 94\%) either increased or decreased along the sediment depth profile with significant statistical support. Flavobacteriia was mostly represented by the family Flavobacteriaceae in this study. Most of the members within Flavobacteriaceae are aerobic, capable of utilizing macromolecules, such as proteins and polysaccharides (Rosenberg et al., 2014d). The three major subordinate families of Cytophagia, Cyclobacteriaceae, Cytophagaceae, and Flammeovirgaceae, share the general physiological feature as aerobic, chemoheterotrophic and capable to degrade a variety of biomacromolecules, such as proteins and polysaccharides, and are widely distributed in aquatic and terrestrial environments (Reichenbach, 2006; Yoon et al., 2011; Rosenberg et al., 2014d). Saprospiraceae and WCHB1-69 mainly made up of Sphingobacteriia class in this study, and the former family is characterized as aerobic heterotrophs with the ability to hydrolyze complex carbon sources, and some of them could form helical gliding filaments and acquire gliding motility for predating other bacteria and algae (Rosenberg et al., 2014d). Gammaproteobacteria was the most abundant class, whose abundance fraction generally decreased along the depth profile in this study. While, the subordinate Chromatiales (mainly represented by Ectothiorhodospiraceae) was enriched in the Depth C layer. Ectothiorhodospiraceae mostly contains the phototrophic purple sulfur bacteria that conduct anoxygenic photosynthesis and some of the members could also live photoheterotrophically depending on a list of limited organic matters. Some of this family could also live purely chemoorganotrophically with oxygen or nitrate as the electron acceptors (Garrity et al., 2006). It will be reasonable that Chromatiales order in this study was enriched in the subsurface sediment layers, due to the strict anaerobic or facultative anaerobic property of this group of bacteria (Rosenberg et al., 2014c).

However, the other three major classes in Gammaproteobacteria, Alteromonadales (mainly represented by Alteromonadaceae), Xanthomonadales and Oceanospirillales, are generally aerobic. Alteromonadaceae is a group of obligately aerobic heterotrophs which prefer nutrient rich environments (Rosenberg et al., 2014c). Xanthomonadales is also a group of obligate aerobic chemoheterotrophs, and has a strict respiratory metabolism with oxygen as the terminal electron acceptor (Garrity et al., 2006). Oceanospirillales is characterized as motile with polar flagella and aerobic, and most of the 


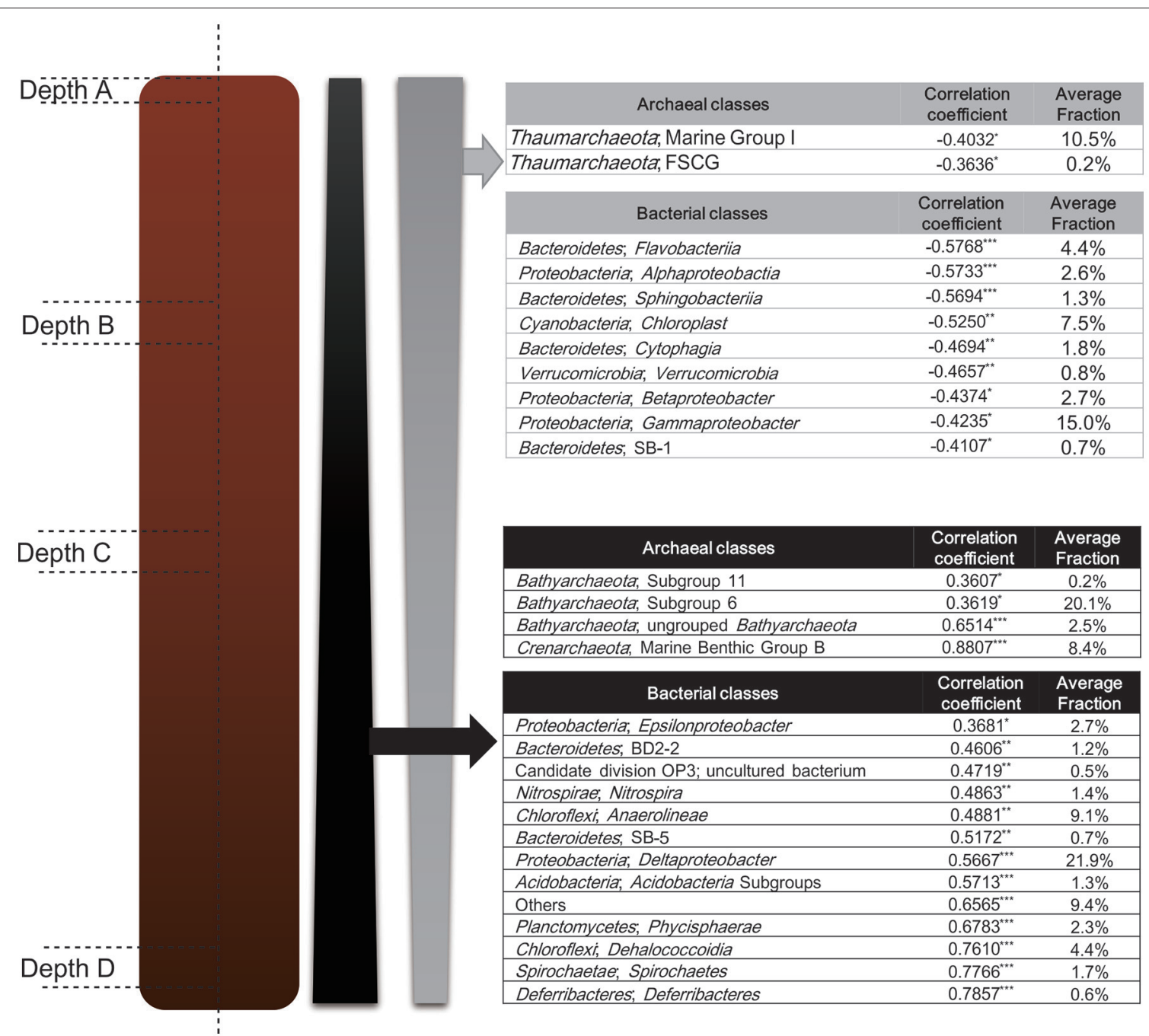

FIGURE 7 | Pearson correlation analysis between sediment layer depth and abundance of groups at the class level for Bacteria and Archaea. Correlation coefficient

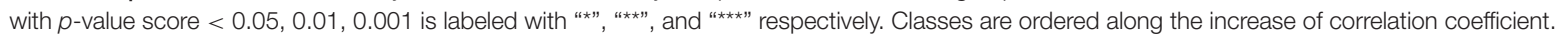

members are found in marine environments (Garrity et al., 2006). Thiotrichales (mainly represented by Thiotrichaceae) and the other Gammaproteobacteria Incertae Sedis are lacking specific physiological description. In this study, the abundance fraction of Gammaproteobacteria as a whole class, showed a decreasing trend toward depth profiles, which might result from its major aerobic components (Figure 7). Burkholderiales, Hydrogenophilales, and Nitrosomonadales were the major components of Betaproteobacteria in this study. Alcaligenaceae comprised the major part of Burkholderiales in this study. It is characterized as aerobic, acquiring a set of strict respiratory elements with oxygen as the final terminal electron acceptor (Brenner et al., 2005). The most abundant genus within Hydrogenophilales was Thiobacillus, which characterized as facultative anaerobic and strictly chemolithotrophic; and it could oxidize reduced sulfur compounds to sulfur/sulfate in the presence of oxygen and often be found in freshwater, estuarine and marine sediments (Rosenberg et al., 2014a). Nitrosomonadales mainly consisted of Nitrosomonadaceae in this study, which is known as a group of aerobic lithoautotrophic ammonia oxidizers (Rosenberg et al., 2014a). Rhodobacteraceae was the major constituent part of Alphaproteobacteria in this study, and they are mainly characterized as aerobic photo/chemoheterotrophs (Rosenberg et al., 2014a). The uncultured Cyanobacteria/Chloroplast relatives in this study were enriched in the surface layer and drastically decreased along the depth profile, which is reasonable for their photosynthesis traits (Whitton and Potts, 2012). Only a few groups of genera within Verrucomicrobia are isolated so far, and most of them are found to be mesophilic carbohydrate degraders. They are widely found in marine and terrestrial habitats or vertebrate digestive tracts, and they are also reported to make up 1$10 \%$ of bacterial $16 \mathrm{~S}$ rRNA gene composition of soils, which indicates their potential important functions in terrestrial 
ecology (Islam et al., 2008; Krieg et al., 2010). The major components of the classes, which showed negative correlation with sediment depth significantly, were aerobic. That could reasonably explicate their distribution preference in the upper layers.

The genera Sulfurimonas and Sulfurovum mainly comprised the class Epsilonproteobacteria in this study. Sulfurimonas is characterized as facultatively anaerobic and could grow chemolithoautotrophically depending on sulfide, sulfur, thiosulfate and hydrogen as electron donors and nitrate, nitrite and oxygen as electron acceptors (Rosenberg et al., 2014b). Sulfurovum is also a group of sulfur oxidizing bacteria with the similar physiology to Sulfurimonas (Rosenberg et al., 2014b). Deltaproteobacteria revealed in this study was mainly comprised of Syntrophobacterales, Desulfobacterales, Desulfobacterales, and Desulfarculales. It contains the largest anaerobic sulfate reducer groups within the above orders. Most of them could chemoorganoheterotrophically degrade and obtain energy from large organic molecules and subsequently metabolize incomplete oxidized products as acetate or complete oxidized products as carbon dioxide (Rosenberg et al., 2014b). Deltaproteobacteria has also been regarded as the representative benthic sediment group, and they prefer to live in sediments of fresh lake rather than water column, which is probably attributed to oxidationreduction potential gradient between water and sediments (Tamaki et al., 2005; Ye et al., 2009). It was also reported that the Syntrophobacterales within Deltaproteobacteria and Chromatiales within Gammaproteobacteria were the most abundant bacterial order in all investigated wetland sediments under both occasional and permanent flooding conditions (Ligi et al., 2014). The Nitrospira and uncultured group within Nitrospiraceae were the major components of Nitrospirae in this study. Nitrospira is a group of chemolithoautotrophic aerobic nitrite oxidizing bacteria. While the other genera within Nitrospiraceae are quite physiologically diverse, for instance, Leptospirillum, chemolithoautotrophic aerobic and acidophilic ferrous ion oxidizers and Thermodesulfovibrio, anaerobic hydrogenotrophic sulfate reducers (Rosenberg et al., 2014d). The major components of Anaerolineae were Anaerolineaceae uncultured groups. This class is Gram-negative, chemoorganotrophic and could only grow under strict anaerobic conditions as described (Yamada et al., 2006). The physiological properties of those uncultured group remain unclear and need further investigation. Dehalococcoidia in this study was mainly comprised of Dehalococcodiales and currently unknown groups within the class. They are strict anaerobic and mesophilic, well-known for their anaerobic respiration on oxidizing hydrogen by halogenated organic compounds (Loeffler et al., 2013). The Chloroflexi phylum was reported to be abundant at deep subsurface sediments as they could occupy up to $70 \%$ of the bacterial $16 \mathrm{~S}$ rRNA gene fraction in the 200,000-year-old Mediterranean sediment (Coolen et al., 2002). Meanwhile, tidal flat sediments from a sampling core lower than $2 \mathrm{~m}$ harbored $60 \%$ Chloroflexi sequences of all bacteria, resembling that of deep subsurface sediments (Wilms et al., 2006). Chloroflexi could utilize recalcitrant organic matters buried in subsurface sediments better than other microorganisms, probably explaining their high abundance in such niches (Wilms et al., 2006). Most Phycisphaerae within Chloroflexi were uncultured groups in this study, with one exception, Phycisphaera mikurensis, which is facultatively anaerobic and could reduce nitrate to nitrite and ferment based on D-xylose; It is fermented on a variety of sugars under aerobic conditions (Fukunaga et al., 2009; Rosenberg et al., 2014d). Spirochaetes was mostly represented by the type genus Spirochaeta in this study. Spirochaeta is obligate or facultative anaerobic, and chemoorganotrophic, feeding on a variety of carbohydrates as carbon and energy sources (Krieg et al., 2010). They are also found indigenous to aquatic freshwater and marine environments, such as marshes, lakes, rivers and etc (Krieg et al., 2010). The class Deferribacteres in this study was mostly represented by Caldithrix. Up to date, only two cultured Caldithrix species have been obtained and they are both obligate anaerobes and chemoorganoheterotrophs, capable of fermenting on di- and poly-saccharides. They could also respire anaerobically depending on hydrogen or acetate as the electron donors and nitrate as the electron acceptor (Rosenberg et al., 2014d). The other uncultured groups, including Acidobacteria Subgroups, Bacteroidetes BD2-2, SB-1 subgroups and Candidate division OP3, all lack clearly described reference on their physiological properties. Collectively, It is revealed that classes which showed positive correlation with sediment depth significantly are mainly obligate or facultative anaerobic, further implicating that it is their physiological traits toward oxygen tolerance that imposes influence on subsurface distribution preference.

The archaeal community also showed a clear stratified distribution as the aerobic groups, including Thaumarchaeota Marine Group I and FSCG, mainly involving with aerobic oxidization of ammonium, were enriched in the surface layer and soon decreased along depth profiles; whereas, Bathyarchaeota Subgroup 6, 11, ungrouped Bathyarchaeota and MBG-B were enriched in the lower layers and increased accordingly along depth profiles (Brochier-Armanet et al., 2012). Both Bathyarchaeota and MBG-B were dominant archaeal groups and distributed worldwide in anoxic marine sediments, hydrothermal vent and methane seep, and etc., (Teske and Sørensen, 2008; He et al., 2016). Besides, they were also discovered universal and dominant in coastal, intertidal sediments and estuarine sediments (Kim et al., 2005; Li et al., 2012). Recent physiological and genomic evidence suggests that both of them have an anaerobic and heterotrophic lifestyle depending on the buried organic carbons (Teske and Sørensen, 2008; Lloyd et al., 2013). The relative fraction of Bathyarchaeota within archaea decreased in shallow sediments in White Oak River (WOR) estuary depth profiles. Meanwhile, it was revealed that Bathyarchaeota Subgroup 6 preferred suboxic sediment layer with limited free sulfide (Lazar et al., 2015). The stratified archaeal community compositional patterns with Thaumarchaeota Marine Group I dominant at surface wetland sediments and Bathyarchaeota dominant at subsurface wetland sediments were also observed in the previously investigations (Webster et al., 2010; Jiang et al., 2011; Li et al., 2012). It was speculated that oxygen availability of sediment layers might be the major factor contributing to 
stratified distribution of archaeal community in Mai Po wetland. Oxygen level is quickly depleted below the surface sediments, and under suboxic conditions, microbial degraders will utilize organic matters using a set of terminal electron accepters with decreasing redox potential, such as $\mathrm{NO}_{3}^{-}, \mathrm{Mn}^{4+}, \mathrm{Fe}^{3+}, \mathrm{SO}_{4}^{2-}$, and $\mathrm{CO}_{3}^{2-}$ (Canfield and Thamdrup, 2009; O'sullivan et al., 2013). Along the geochemical variation of depth profile, microbial community pattern will be influenced accordingly, whilst, the most influential factors would be the respiratory condition with the presence/absence of oxygen, which largely stratifies microbial community compositions (Canfield and Thamdrup, 2009; O’sullivan et al., 2013).

\section{CONCLUSION}

In conclusion, the present study gives a comprehensive investigation on the bacterial and archaeal community abundance, composition and diversity in Mai Po wetland sediments, and has compared their distribution patterns in terms of depth profiles, sediment types, sampling locations and seasonality. The abundance of bacterial $16 \mathrm{~S}$ rRNA genes in individual sampling sites shows a clear decreasing trend from surface layers to subsurface layers, irrespective of sampling sites, seasonality and sediment types. The most abundant five phyla of both bacterial and archaeal communities remain stable in terms of different sediment types. The alpha and beta diversity pattern revealed by the bacterial and archaeal community structure suggests that there is a weak seasonal dynamic of microbial community in Mai Po wetland. Meanwhile, sediment layer depth and seasonality influence the most on the bacterial community, while $\mathrm{pH}$ is the most influential factor on shaping the archaeal community. Stratified distribution patterns on community abundance and composition for both bacterial and archaeal communities are clear, as the aerobic groups dominate the surface layers, and anaerobic groups dominate the subsurface layers. Thaumarchaeota Marine Group I are dominant at surface sediments and Bathyarchaeota and MBG-B

\section{REFERENCES}

Alongi, D. M. (2014). Carbon cycling and storage in mangrove forests. Ann. Rev. Mar. Sci. 6, 195-219. doi: 10.1146/annurev-marine-010213-135020

Angiuoli, S. V., Matalka, M., Gussman, A., Galens, K., Vangala, M., Riley, D. R., et al. (2011). CloVR: a virtual machine for automated and portable sequence analysis from the desktop using cloud computing. BMC Bioinformatics 12:356. doi: 10.1186/1471-2105-12-356

Ansola, G., Arroyo, P., and Saenz De Miera, L. E. (2014). Characterisation of the soil bacterial community structure and composition of natural and constructed wetlands. Sci. Total Environ. 473, 63-71. doi: 10.1016/j.scitotenv.2013. 11.125

Arroyo, P., Saenz De Miera, L. E., and Ansola, G. (2015). Influence of environmental variables on the structure and composition of soil bacterial communities in natural and constructed wetlands. Sci. Total Environ. 506, 380-390. doi: 10.1016/j.scitotenv.2014.11.039

Bengtson, P., Sterngren, A. E., and Rousk, J. (2012). Archaeal abundance across a $\mathrm{pH}$ gradient in an arable soil and its relationship to bacterial and fungal growth rates. Appl. Environ. Microbiol. 78, 5906-5911. doi: 10.1128/AEM. 01476-12 are dominant at subsurface. The stratified distribution pattern of microbial community revealed from this study might result from oxygen availability and gradient distribution of terminal electron accepters along the depth profile. This phenomenon has also been observed universally. More precise biogeochemical profiling, such as profiling of in situ physicochemical parameters and biogeochemical activity rates, on depth profiles and especially on deeper sediment layers should be conducted; and combined with advanced sequencing techniques, more insightful outcomes will be achieved on the stratified distribution of microbial communities in coastal wetlands.

\section{AUTHOR CONTRIBUTIONS}

ZZ, JG, and ML conceived this study. ZZ and HM performed the sampling and physicochemical measurement. ZZ performed the original data analysis and drafted the original manuscript. HM, YL, JG, and ML contributed together to the final manuscript by discussing and rewriting several essential parts.

\section{ACKNOWLEDGMENTS}

We thank Ms. Kelly Lau for her technical help and Prof. Xiangzhen $\mathrm{Li}$ and his lab colleagues from Chengdu Institute of Biology, Chinese Academy of Sciences for their support on MiSeq sequencing and related bioinformatic analysis. This research was supported by National Natural Science Foundation of China (grant no. 41506163, 31622002), Natural Science Foundation of Guangdong Province (grant no. 2014A030310056, 2014A030310231), and Shenzhen Science and Technology Innovation Commission (grant no. KQCX2015032416053646).

\section{SUPPLEMENTARY MATERIAL}

The Supplementary Material for this article can be found online at: https://www.frontiersin.org/articles/10.3389/fmicb. 2017.02148/full\#supplementary-material
Bhattacharyya, A., Majumder, N. S., Basak, P., Mukherji, S., Roy, D., Nag, S., et al. (2015). Diversity and distribution of Archaea in the mangrove sediment of Sundarbans. Archaea 2015:968582. doi: 10.1155/2015/968582

Brenner, D. J., Krieg, N. R., and Staley, J. T. (2005). Bergey's Manual ${ }^{\circledR}$ of Systematic Bacteriology. New York, NY: Springer.

Brochier-Armanet, C., Gribaldo, S., and Forterre, P. (2012). Spotlight on the Thaumarchaeota. ISME J. 6, 227-230. doi: 10.1038/ismej.2011.145

Canfield, D. E., and Thamdrup, B. (2009). Towards a consistent classification scheme for geochemical environments, or, why we wish the term 'suboxic' would go away. Geobiology 7, 385-392. doi: 10.1111/j.1472-4669.2009.00214.x

Cao, H., Hong, Y., Li, M., and Gu, J.-D. (2012). Community shift of ammoniaoxidizing bacteria along an anthropogenic pollution gradient from the Pearl River Delta to the South China Sea. Appl. Microbiol. Biotechnol. 94, 247-259. doi: 10.1007/s00253-011-3636-1

Caporaso, J. G., Kuczynski, J., Stombaugh, J., Bittinger, K., Bushman, F. D., Costello, E. K., et al. (2010). QIIME allows analysis of highthroughput community sequencing data. Nat. Methods 7, 335-336. doi: $10.1038 /$ nmeth.f.303

Caporaso, J. G., Lauber, C. L., Walters, W. A., Berg-Lyons, D., Huntley, J., Fierer, N., et al. (2012). Ultra-high-throughput microbial community 
analysis on the Illumina HiSeq and MiSeq platforms. ISME J. 6, 1621-1624. doi: 10.1038/ismej.2012.8

Cheung, K., Poon, B., Lan, C., and Wong, M. (2003). Assessment of metal and nutrient concentrations in river water and sediment collected from the cities in the Pearl River Delta, South China. Chemosphere 52, 1431-1440. doi: 10.1016/S0045-6535(03)00479-X

Cole, J. R., Wang, Q., Fish, J. A., Chai, B., Mcgarrell, D. M., Sun, Y., et al. (2014). Ribosomal Database Project: data and tools for high throughput rRNA analysis. Nucleic Acids Res. 42, D633-D642. doi: 10.1093/nar/gkt1244

Coolen, M. J. L., Cypionka, H., Sass, A. M., Sass, H., and Overmann, J. (2002). Ongoing modification of Mediterranean Pleistocene sapropels mediated by prokaryotes. Science 296, 2407-2410. doi: 10.1126/science.1071893

DeLong, E. F. (1992). Archaea in coastal marine environments. Proc. Natl. Acad. Sci. U.S.A. 89, 5685-5689. doi: 10.1073/pnas.89.12.5685

Ding, X., Peng, X.-J., Jin, B.-S., Xiao, M., Chen, J.-K., Li, B., et al. (2015). Spatial distribution of bacterial communities driven by multiple environmental factors in a beach wetland of the largest freshwater lake in China. Front. Microbio. 6:129. doi: $10.3389 /$ fmicb.2015.00129

Dowd, S. E., Callaway, T. R., Wolcott, R. D., Sun, Y., Mckeehan, T., Hagevoort, R. G., et al. (2008). Evaluation of the bacterial diversity in the feces of cattle using 16S rDNA bacterial tag-encoded FLX amplicon pyrosequencing (bTEFAP). BMC Microbiol. 8:125. doi: 10.1186/1471-2180-8-125

Drenovsky, R. E., Vo, D., Graham, K. J., and Scow, K. M. (2004). Soil water content and organic carbon availability are major determinants of soil microbial community composition. Microb. Ecol. 48, 424-430. doi: 10.1007/s00248-003-1063-2

Edgar, R. C. (2010). Search and clustering orders of magnitude faster than BLAST. Bioinformatics 26, 2460-2461. doi: 10.1093/bioinformatics/btq461

Fierer, N., Schimel, J. P., and Holden, P. A. (2003). Influence of drying-rewetting frequency on soil bacterial community structure. Microb. Ecol. 45, 63-71. doi: 10.1007/s00248-002-1007-2

Fukunaga, Y., Kurahashi, M., Sakiyama, Y., Ohuchi, M., Yokota, A., and Harayama, S. (2009). Phycisphaera mikurensis gen. nov., sp nov., isolated from a marine alga, and proposal of Phycisphaeraceae fam. nov., Phycisphaerales ord. nov and Phycisphaerae classis nov in the phylum Planctomycetes. J. Gen. Appl. Microbiol. 55, 267-275. doi: 10.2323/jgam.55.267

Garrity, G., Staley, J. T., Boone, D. R., De Vos, P., Goodfellow, M., Rainey, F. A., et al. (2006). Bergey's Manual ${ }^{\circledR}$ of Systematic Bacteriology. New York, NY: Springer.

He, Y., Li, M., Perumal, V., Feng, X., Fang, J., Xie, J., et al. (2016). Genomic and enzymatic evidence for acetogenesis among multiple lineages of the archaeal phylum Bathyarchaeota widespread in marine sediments. Nat. Microbiol. 1:16035. doi: 10.1038/nmicrobiol.2016.35

Holguin, G., Vazquez, P., and Bashan, Y. (2001). The role of sediment microorganisms in the productivity, conservation, and rehabilitation of mangrove ecosystems: an overview. Biol. Fertility Soils 33, 265-278. doi: $10.1007 / \mathrm{s} 003740000319$

Islam, T., Jensen, S., Reigstad, L. J., Larsen, O., and Birkeland, N.-K. (2008). Methane oxidation at $55^{\circ} \mathrm{C}$ and $\mathrm{pH} 2$ by a thermoacidophilic bacterium belonging to the Verrucomicrobia phylum. Proc. Natl. Acad. Sci. U.S.A. 105, 300-304. doi: 10.1073/pnas.0704162105

Jia, M., Zhang, Y., Wang, Z., Song, K., and Ren, C. (2014). Mapping the distribution of mangrove species in the Core Zone of Mai Po Marshes Nature Reserve, Hong Kong, using hyperspectral data and high-resolution data. Int. J. Appl. Earth OBS 33, 226-231. doi: 10.1016/j.jag.2014.06.006

Jiang, L., Zheng, Y., Chen, J., Xiao, X., and Wang, F. (2011). Stratification of Archaeal communities in shallow sediments of the Pearl River Estuary, Southern China. Antonie Van Leeuwenhoek 99, 739-751. doi: $10.1007 /$ s10482-011-9548-3

Jiang, X.-T., Peng, X., Deng, G.-H., Sheng, H.-F., Wang, Y., Zhou, H.-W., et al. (2013). Illumina sequencing of 16S rRNA tag revealed spatial variations of bacterial communities in a mangrove wetland. Microb. Ecol. 66, 96-104. doi: 10.1007/s00248-013-0238-8

Kim, B. S., Oh, H. M., Kang, H., and Chun, J. (2005). Archaeal diversity in tidal flat sediment as revealed by $16 \mathrm{~S}$ rDNA analysis. J. Microbiol. 43, 144-151.

Krieg, N. R., Staley, J. T., Brown, D. R., Hedlund, B. P., Paster, B. J., Ward, N. L., et al. (2010). Bergey's Manual ${ }^{\circledR}$ of Systematic Bacteriology. New York, NY: Springer.
Lau, S., and Chu, L. (1999). Water quality degradation at the Mai Po Marshes Nature Reserve (Hong Kong) with reference to nutrient enrichment. Hydrobiologia 403, 195-203. doi: 10.1023/A:1003759215909

Lazar, C. S., Biddle, J. F., Meador, T. B., Blair, N., Hinrichs, K.-U., and Teske, A. P. (2015). Environmental controls on intragroup diversity of the uncultured benthic archaea of the miscellaneous Crenarchaeotal group lineage naturally enriched in anoxic sediments of the White Oak River estuary (North Carolina, USA). Environ. Microbiol. 17, 2228-2238. doi: 10.1111/1462-2920. 12659

Lee, J. H. W., Harrison, P. J., Kuang, C., and Yin, K. (2006). "Eutrophication dynamics in Hong Kong coastal waters: physical and biological interactions," in Environment in Asia Pacific Harbours, ed E. Wolanski (Springer), $187-206$.

Lee, S.-Y. (1999). "The Mangrove Ecosystem of Deep Bay and the Mai Po Marshes, Hong Kong," in Proceedings of the International Workshop on the Mangrove Ecosystem of Deep Bay and the Mai Po Marshes, (Hong Kong: Hong Kong University Press).

Li, M., Hong, Y., Cao, H., and Gu, J.-D. (2013). Community structures and distribution of anaerobic ammonium oxidizing and nirS-encoding nitritereducing bacteria in surface sediments of the South China Sea. Microb. Ecol. 66, 281-296. doi: 10.1007/s00248-012-0175-y

Li, Q., Wang, F., Chen, Z., Yin, X., and Xiao, X. (2012). Stratified active archaeal communities in the sediments of Jiulong River estuary, China. Front. Microbio. 3:311. doi: $10.3389 /$ fmicb.2012.00311

Liang, Y., and Wong, M. H. (2003). Spatial and temporal organic and heavy metal pollution at Mai Po Marshes Nature Reserve, Hong Kong. Chemosphere 52, 1647-1658. doi: 10.1016/S0045-6535(03)00505-8

Ligi, T., Oopkaup, K., Truu, M., Preem, J.-K., Nolvak, H., Mitsch, W. J., et al. (2014). Characterization of bacterial communities in soil and sediment of a created riverine wetland complex using high-throughput 16S rRNA amplicon sequencing. Ecol. Eng. 72, 56-66. doi: 10.1016/j.ecoleng.2013. 09.007

Lloyd, K. G., Schreiber, L., Petersen, D. G., Kjeldsen, K. U., Lever, M. A., Steen, A. D., et al. (2013). Predominant archaea in marine sediments degrade detrital proteins. Nature 496, 215-218. doi: 10.1038/nature12033

Loeffler, F. E., Yan, J., Ritalahti, K. M., Adrian, L., Edwards, E. A., Konstantinidis, K. T., et al. (2013). Dehalococcoides mccartyi gen. nov., sp nov., obligately organohalide-respiring anaerobic bacteria relevant to halogen cycling and bioremediation, belong to a novel bacterial class, Dehalococcoidia classis nov., order Dehalococcoidales ord. nov and family Dehalococcoidaceae fam. nov., within the phylum Chloroflexi. Int. J. Syst. Evol. Microbiol. 63, 625-635. doi: 10.1099/ijs.0.034926-0

Lu, X.-M., Chen, C., Zheng, T.-L., and Chen, J.-J. (2016). Temporal-spatial variation of bacterial diversity in estuary sediments in the south of Zhejiang Province, China. Appl. Microbiol. Biotechnol. 100, 2817-2828. doi: $10.1007 / \mathrm{s} 00253-015-7103-2$

Magoc, T., and Salzberg, S. L. (2011). FLASH: fast length adjustment of short reads to improve genome assemblies. Bioinformatics 27, 2957-2963. doi: 10.1093/bioinformatics/btr507

Motulsky, H. (1999). Analyzing Data with GraphPad Prism. San Diego, CA: GraphPad Software Incorporated.

Nadkarni, M. A., Martin, F. E., Jacques, N. A., and Hunter, N. (2002). Determination of bacterial load by real-time PCR using a broadrange (universal) probe and primers set. Microbiology 148, 257-266. doi: 10.1099/00221287-148-1-257

Nedwell, D. B., Blackburn, T. H., and Wiebe, W. J. (1994). Dynamic nature of the turnover of organic carbon, nitrogen and sulphur in the sediments of a Jamaican mangrove forest. Mar. Ecol. Prog. Ser. 110, 223-231. doi: $10.3354 /$ meps 110223

Oksanen, J., Kindt, R., Legendre, P., O'hara, B., Stevens, M. H. H., Oksanen, M. J., et al. (2007). The Vegan PackAge. Community Ecology Package, 631-637.

O'sullivan, L. A., Sass, A. M., Webster, G., Fry, J. C., Parkes, R. J., and Weightman, A. J. (2013). Contrasting relationships between biogeochemistry and prokaryotic diversity depth profiles along an estuarine sediment gradient. FEMS Microbiol. Ecol. 85, 143-157. doi: 10.1111/1574-6941.12106

Quast, C., Pruesse, E., Yilmaz, P., Gerken, J., Schweer, T., Yarza, P., et al. (2013). The SILVA ribosomal RNA gene database project: improved data processing and web-based tools. Nucleic Acids Res. 41, D590-D596. doi: 10.1093/nar/gks1219 
Reef, R., Feller, I. C., and Lovelock, C. E. (2010). Nutrition of mangroves. Tree Physiol. 30, 1148-1160. doi: 10.1093/treephys/tpq048

Reichenbach, H. (2006). "The Order Cytophagales," in The Prokaryotes: Vol. 7, Proteobacteria: Delta, Epsilon Subclass, eds M. Dworkin, S. Falkow, E. Rosenberg, K.-H. Schleifer, and E. Stackebrandt (New York, NY: Springer New York), 549-590.

Rosenberg, E., Delong, E. F., Lory, S., Stackebrandt, E., and Thompson, F. (2014a). The Prokaryotes: Alphaproteobacteria and Betaproteobacteria. Berlin; Heidelberg: Springer.

Rosenberg, E., Delong, E. F., Lory, S., Stackebrandt, E., and Thompson, F. (2014b). The Prokaryotes: Deltaproteobacteria and Epsilonproteobacteria. Berlin; Heidelberg: Springer.

Rosenberg, E., Delong, E. F., Lory, S., Stackebrandt, E., and Thompson, F. (2014c). The Prokaryotes: Gammaproteobacteria. Berlin; Heidelberg: Springer.

Rosenberg, E., Delong, E. F., Lory, S., Stackebrandt, E., and Thompson, F. (2014d). The Prokaryotes: Other Major Lineages of Bacteria and The Archaea. Berlin; Heidelberg: Springer.

Sahoo, K., and Dhal, N. K. (2009). Potential microbial diversity in mangrove ecosystems: a review. Indian. J. Mar. Sci. 38, 249-256.

Sanders, C. J., Eyre, B. D., Santos, I. R., Machado, W., Luiz-Silva, W., Smoak, J. M., et al. (2014). Elevated rates of organic carbon, nitrogen, and phosphorus accumulation in a highly impacted mangrove wetland. Geophys. Res. Lett. 41, 2475-2480. doi: 10.1002/2014GL0 59789

Schloss, P. D., Westcott, S. L., Ryabin, T., Hall, J. R., Hartmann, M., Hollister, E. B., et al. (2009). Introducing mothur: open-source, platformindependent, community-supported software for describing and comparing microbial communities. Appl. Environ. Microbiol. 75, 7537-7541. doi: 10.1128/AEM.01541-09

Segata, N., Izard, J., Waldron, L., Gevers, D., Miropolsky, L., Garrett, W. S., et al. (2011). Metagenomic biomarker discovery and explanation. Genome Biol. 12:R60. doi: 10.1186/gb-2011-12-6-r60

Sims, A., Zhang, Y., Galaraj, S., Brown, P. B., and Hu, Z. (2013). Toward the development of microbial indicators for wetland assessment. Water Res. 47, 1711-1725. doi: 10.1016/j.watres.2013.01.023

Takai, K., and Horikoshi, K. (2000). Rapid detection and quantification of members of the archaeal community by quantitative PCR using fluorogenic probes. Appl. Environ. Microbiol. 66:5066. doi: 10.1128/AEM.66.11.506 6-5072.2000

Tam, N. F. Y., Wong, Y. S., Lan, C. Y., and Wang, L. N. (1998). Litter production and decomposition in a subtropical mangrove swamp receiving wastewater. $J$. Exp. Mar. Biol. Ecol. 226, 1-18. doi: 10.1016/S0022-0981(97)00233-5

Tamaki, H., Sekiguchi, Y., Hanada, S., Nakamura, K., Nomura, N., Matsumura, M., et al. (2005). Comparative analysis of bacterial diversity in freshwater sediment of a shallow eutrophic lake by molecular and improved cultivation-based techniques. Appl. Environ. Microbiol. 71, 2162-2169. doi: 10.1128/AEM.71.4.2162-2169.2005

Teske, A., and Sørensen, K. B. (2008). Uncultured archaea in deep marine subsurface sediments: have we caught them all? ISME J. 2, 3-18. doi: $10.1038 /$ ismej.2007.90

Therneau, T., Atkinson, B., Ripley, B., Oksanen, J., and De'ath, G. (2012). Mvpart: Multivariate Partitioning. R package version 1.6-0.

Tripathi, B. M., Kim, M., Lai-Hoe, A., Shukor, N. A., Rahim, R. A., Go, R., et al. (2013). pH dominates variation in tropical soil archaeal diversity and community structure. FEMS Microbiol. Ecol. 86, 303-311. doi: $10.1111 / 1574-6941.12163$
Wang, Y.-F., Feng, Y.-Y., Ma, X., and Gu, J.-D. (2013). Seasonal dynamics of ammonia/ammonium-oxidizing prokaryotes in oxic and anoxic wetland sediments of subtropical coastal mangrove. Appl. Microbiol. Biotechnol. 97, 7919-7934. doi: 10.1007/s00253-012-4510-5

Wang, Y., and Qian, P.-Y. (2009). Conservative fragments in bacterial 16S rRNA genes and primer design for $16 \mathrm{~S}$ ribosomal DNA amplicons in metagenomic studies. PLoS ONE 4:e0007401. doi: 10.1371/journal.pone.0007401

Wang, Y., Sheng, H.-F., He, Y., Wu, J.-Y., Jiang, Y.-X., Tam, N. F.-Y., et al. (2012). Comparison of the levels of bacterial diversity in freshwater, intertidal wetland, and marine sediments by using millions of illumina tags. Appl. Environ. Microbiol. 78, 8264-8271. doi: 10.1128/AEM.01821-12

Webster, G., Rinna, J., Roussel, E. G., Fry, J. C., Weightman, A. J., and Parkes, R. J. (2010). Prokaryotic functional diversity in different biogeochemical depth zones in tidal sediments of the Severn Estuary, UK, revealed by stable-isotope probing. FEMS Microbiol. Ecol. 72, 179-197. doi: 10.1111/j.1574-6941.2010.00848.x

Whitton, B. A., and Potts, M. (2012). "Introduction to the Cyanobacteria," in Ecology of Cyanobacteria II, ed B. A. Whitton (Dordrecht: Springer), 1-13.

Wilms, R., Kopke, B., Sass, H., Chang, T. S., Cypionka, H., and Engelen, B. (2006). Deep biosphere-related bacteria within the subsurface of tidal flat sediments. Environ. Microbiol. 8, 709-719. doi: 10.1111/j.1462-2920.2005.00949.x

Yamada, T., Sekiguchi, Y., Hanada, S., Imachi, H., Ohashi, A., Harada, H., et al. (2006). Anaerolinea thermolimosa sp nov., Levilinea saccharolytica gen. nov., sp nov and Leptolinea tardivitalis gen. nov., so. nov., novel filamentous anaerobes, and description of the new classes Anaerolineae classis nov and Caldilineae classis nov in the bacterial phylum Chloroflexi. Int. J. Syst. Evol. Microbiol. 56, 1331-1340. doi: 10.1099/ijs.0.64169-0

Yan, B., Hong, K., and Yu, Z.-N. (2006). Archaeal communities in mangrove soil characterized by $16 \mathrm{~S}$ rRNA gene clones. J. Microbiol. 44, 566-571.

Ye, W., Liu, X., Lin, S., Tan, J., Pan, J., Li, D., et al. (2009). The vertical distribution of bacterial and archaeal communities in the water and sediment of Lake Taihu. FEMS Microbiol. Ecol. 70, 263-276. doi: 10.1111/j.1574-6941.2009.00761.x

Yoon, J., Adachi, K., Park, S., Kasai, H., and Yokota, A. (2011). Aureibacter tunicatorum gen. nov., sp nov., a marine bacterium isolated from a coral reef sea squirt, and description of Flammeovirgaceae fam. nov. Int. J. Syst. Evol. Microbiol. 61, 2342-2347. doi: 10.1099/ijs.0.027573-0

Zheng, G. J., Lam, M. H. W., Lam, P. K. S., Richardson, B. J., Man, B. K. W., and Li, A. M. Y. (2000). Concentrations of persistent organic pollutants in surface sediments of the mudflat and mangroves at Mai Po marshes nature reserve, Hong Kong. Mar. Pollut. Bull. 40, 1210-1214. doi: 10.1016/S0025-326X(00)00190-9

Zhou, Y.-W., Zhao, B., Peng, Y.-S., and Chen, G.-Z. (2010). Influence of mangrove reforestation on heavy metal accumulation and speciation in intertidal sediments. Mar. Pollut. Bull. 60, 1319-1324. doi: 10.1016/j.marpolbul.2010.03.010

Conflict of Interest Statement: The authors declare that the research was conducted in the absence of any commercial or financial relationships that could be construed as a potential conflict of interest.

Copyright () 2017 Zhou, Meng, Liu, Gu and Li. This is an open-access article distributed under the terms of the Creative Commons Attribution License (CC BY). The use, distribution or reproduction in other forums is permitted, provided the original author(s) or licensor are credited and that the original publication in this journal is cited, in accordance with accepted academic practice. No use, distribution or reproduction is permitted which does not comply with these terms. 